\title{
Smoothened and ARL13B are critical in mouse for superior cerebellar peduncle targeting
}

\author{
Sarah K. Suciu ${ }^{*},+, \ddagger$ Alyssa B. Long ${ }^{\dagger, \ddagger}$ and Tamara Caspary ${ }^{\dagger}$ \\ *Genetics and Molecular Biology Graduate Program, ${ }^{\dagger}$ Department of Human Genetics, \\ Emory University, Atlanta, GA 30322, ${ }^{\ddagger}$ These authors contributed equally
}

\section{ORCID ID:}

Suciu: 0000-0002-2416-9519

Long: 0000-0002-4467-4213

Caspary: 0000-0002-6579-7589

\section{Summary statement}

Joubert syndrome is diagnosed by the hindbrain "molar tooth sign" malformation. Using mouse models, we show loss of the ciliary GTPase ARL13B, mutations in which lead to Joubert syndrome, result in two features of the molar tooth sign: hypoplasia of the cerebellar vermis and inappropriate targeting of the superior cerebellar peduncles. Furthermore, we demonstrate that loss of vertebrate Hedgehog signaling may be the underlying disrupted mechanism as we extend its role in axon guidance to the superior cerebellar peduncles. 
Running title ( $\sim 35$ characters, including spaces):

SMO and ARL13B in SCP targeting

\section{Key words/phrases (up to ten):}

molar tooth sign, Joubert syndrome, Smo, ARL13B, SCP targeting, cerebellar vermis

\section{Corresponding author:}

Tamara Caspary

Department of Human Genetics

615 Michael Street, Suite 301

Atlanta, GA 30322

404-727-9862

tcaspar@emory.edu 


\section{Abstract}

2 Patients with the ciliopathy Joubert syndrome present with physical anomalies,

3 intellectual disability, and a hindbrain malformation described as the "molar tooth sign"

4 due to its appearance on an MRI. This radiological abnormality results from a regulatory GTPase established to regulate cell fate, cell proliferation and axon guidance

8 through vertebrate Hedgehog signaling. In patients, mutations in $A R L 13 B$ cause Joubert

9 syndrome. In order to understand the etiology of the molar tooth sign, we used mouse

10 models to investigate the role of ARL13B during cerebellar development. We found

11 ARL13B regulates superior cerebellar peduncle targeting and these fiber tracts require

12 Hedgehog signaling for proper guidance. However, in mouse the Joubert-causing R79Q

13 mutation in ARL13B does not disrupt Hedgehog signaling nor does it impact tract

14 targeting. We found a small cerebellar vermis in mice lacking ARL13B function but no

15 cerebellar vermis hypoplasia in mice expressing the Joubert-causing R79Q mutation.

16 Additionally, mice expressing a cilia-excluded variant of ARL13B that transduces

17 Hedgehog normally, showed normal tract targeting and vermis width. Taken together,

18 our data indicate that ARL13B is critical for control of cerebellar vermis width as well as

19 superior cerebellar peduncle axon guidance, likely via Hedgehog signaling. Thus, our

20 work highlights the complexity of ARL13B in molar tooth sign etiology. 


\section{INTRODUCTION}

Joubert Syndrome and Related Disorders (JSRD) are recessive congenital

23 disorders with a variety of symptoms including developmental delay, intellectual

24 disability, abnormal respiratory rhythms, ataxia, oculomotor apraxia, polydactyly, craniofacial defects, retinal dystrophy, nephronophthisis, and hepatic fibrosis (Parisi et al. 2007, Bachmann-Gagescu et al. 2020). While the exact prevalence of JSRD is not

27 known, published statistics range from 1:80,000 to 1:100,000, but these may be underestimates as suggested by a recent study (Brancati et al. 2010, Nuovo et al. 2020). The characteristic neuroanatomical feature of JSRD is the molar tooth sign (MTS), which is caused by hypoplasia of the cerebellar vermis and thickened, elongated

31 superior cerebellar peduncles (SCPs) that fail to decussate (Maria et al. 1997; Yachnis and Rorke 1999; Poretti et al. 2007). However, little is known about the mechanistic

33 etiology of this hindbrain malformation. This is especially significant as several symptoms of JSRD arise from defects in the hindbrain: cerebellar dysfunction commonly causes ataxia and hypotonia, while some patients manifest life-threatening breathing problems (Parisi 2019).

To date, mutations in over 35 genes cause JSRD, and their associated proteins

38 almost always localize to the primary cilium or the centrosome (Parisi 2019). Thus, JSRD is classified as a ciliopathy, a category of human disease stemming from ciliary

40 dysfunction. One of the genes implicated in JSRD is $A R L 13 B$, which encodes a

41 regulatory GTPase highly enriched in cilia (Cantagrel et al. 2008; Bachmann-Gagescu

42 et al. 2015; Thomas et al. 2015; Shaheen et al. 2016; Rafiullah et al. 2017). As a

43 GTPase, ARL13B is expected to have multiple effector proteins which interact with 
44 specific ARL13B residues. ARL13B can function as a guanine exchange factor (GEF)

45 for ARL3, mutations in which also lead to JSRD (Gotthardt et al. 2015; Ivanova et al.

46 2017). JSRD-causing mutations in either ARL3 or ARL13B can disrupt their interaction

47 or ARL13B's GEF activity, consistent with the notion that specific ARL13B function is

48 affected by JS-causing point mutations (Gotthardt et al. 2015; Ivanova et al. 2017;

49 Alkanderi et al. 2018). Most JSRD-causing ARL13B mutations cluster within the

50 protein's GTPase domain, although two are located in the coiled coil domains in the C

51 terminal half of the protein (Cantagrel et al. 2008; Bachmann-Gagescu et al. 2015;

52 Thomas et al. 2015; Shaheen et al. 2016; Rafiullah et al. 2017). ARL13B complexes

53 with the inositol phosphatase INPP5E, which is also implicated in causing JSRD (Bielas

54 et al. 2009; Humbert et al. 2012). ARL13B is critical for targeting INPP5E to cilia and

JSRD-causing ARL13B mutations disrupt INPP5E ciliary targeting (Humbert et al.

57 most JSRD-causing mutations are within its phosphatase domain (Bielas et al. 2009;

58 Chavez et al. 2015; Garcia-Gonzalo et al. 2015). Other proteins implicated in JSRD also

59 affect ciliary targeting with many functioning at the transition zone, supporting the notion

60 that abnormal ciliary traffic leading to defective signaling underlies JSRD (Arts et al.

61 2007; Delous et al. 2007; Garcia-Gonzalo et al. 2011; Hopp et al. 2011; Srour et al.

62 2012; Roberson et al. 2015).

63 The mechanistic connection between the cilia-related proteins implicated in

64 JSRD and the MTS are elusive in part because distinct biological processes are at play.

65 Abnormal proliferation may underlie the hypoplastic cerebellar vermis whereas defective

66 axonal targeting is likely involved in the abnormal SCP tracts. One signaling pathway 
67 potentially linked to both processes is vertebrate Hedgehog (Hh) which relies on cilia

68 (Huangfu et al. 2003). Sonic hedgehog (Shh) is a mitogenic cue that controls

69 proliferation in the developing cerebellum so its misregulation could underlie the

70 cerebellar hypoplasia (Dahmane and Ruiz i Altaba 1999; Wechsler-Reya and Scott

71 1999; Kenney and Rowitch 2000). While the SCP tracts that normally project from the

72 deep cerebellar nuclei to the contralateral thalamus are guided by unknown signals,

73 Shh is a known commissural axon guidance cue (Charron et al. 2003). JSRD patients

74 can also display axon guidance defects in decussation of the pyramidal tracts (Yachnis

75 and Rorke 1999; Poretti et al. 1997).

$A R L 13 B$ and INPP5E, encoding ciliary proteins linked to JSRD, are known to regulate vertebrate $\mathrm{Hh}$ signaling. In mouse models, ARL13B loss disrupts cell fate specification in the neural tube, proliferation of the cerebellar granule precursor cells in the cerebellum and Shh-directed guidance of commissural axons in the spinal cord (Caspary et al. 2007; Bay et al. 2018; Ferent et al. 2019). These data support a model

81 whereby disruption of Shh signaling by ARL13B mutation could provide a single

82 mechanism underlying the MTS. This model is bolstered by the fact that additional

83 phenotypes exhibited by JSRD patients, such as craniofacial defects or polydactyly, can

84 arise from aberrant Hh signaling (Valente et al. 2008; Lan and Jiang 2009; Lipinski et al. 85 2010).

As attractive as a Hh-based model for JSRD may be, not all the data support that

87 JSRD phenotypes result from misregulation of Hh signaling. Some features of JSRD,

88 such as the renal and liver anomalies, are not clearly due to misregulation of Hh

89 signaling (Doherty 2009; Breslow et al. 2018). Additionally, of over 35 genes implicated 
90 in JSRD, only 22 play some role in Hh pathway regulation (Davey et al. 2006; Reiter

91 and Skarnes 2006; Caspary et al. 2007; Vierkotten et al. 2007; Huang et al. 2009;

92 Weatherbee et al. 2009; Bimonte et al. 2011; Dowdle et al. 2011; Sang et al. 2011; Chih

93 et al. 2011; Christopher et al. 2012; Thomas et al. 2012; Abdelhamed et al. 2013; Hynes

94 et al. 2014; Wu et al. 2014; Chavez et al. 2015; Garcia-Gonzalo et al. 2015; Asadollahi

95 et al. 2018; Frikstad et al. 2019; Munoz-Estrada and Ferland 2019). Some of these links

96 are tenuous. For example, mouse Arl3 mutants mislocalize the Hh transcription factor,

97 GLI3, in their cilia yet do not exhibit any of the phenotypes normally displayed by

98 mutants in the Hh pathway (Schrick et al. 2006, Lai et al. 2011; Schwarz et al. 2017).

99 Additional signaling pathways are linked to cilia including others known to be important

100 in cell proliferation and axon guidance. Loss of either of the JSRD-linked genes Ahi1 or

101 Cep290 in mouse leads to a small cerebellar vermis due to aberrant Wnt signaling

102 (Lancaster et al. 2011; Ramsbottom et al. 2020). Possible JSRD-causing mutations in

103 Znf423 are associated with defects in Wnt, BMP and retinoic acid signaling (Hata et al.

104 2000, Huang et al. 2009, Casoni et al. 2020, Deshpande et al. 2020). Conditional Arl13b

105 or Inpp5e deletion in the SCPs results in their disorganization and thickening through

106 misregulation of ciliary PI3 kinase and AKT (Guo et al. 2019).

107 Ciliopathies are well established to be genetically complex. JSRD patients with

108 different ARL13B mutations can display distinct phenotypes, such as obesity in an

109 individual expressing $A R L 13 B^{\mathrm{Y} 86 \mathrm{C}}$ and occipital encephalocele in a patient expressing

$110 \quad A^{2} 13 B^{R 79 Q}$ (Cantagrel et al. 2008; Thomas et al. 2015). This is further exemplified in

111 cases of related individuals carrying the same mutation but exhibiting different

112 phenotypes and even diagnoses. For example, JSRD-causing mutations in TMEM67 
$113(\mathrm{R} 208 \mathrm{X})$ and TMEM216 $(\mathrm{R} 73 \mathrm{H})$ can also cause the more severe disease Meckel

114 syndrome (Consugar et al. 2007; Otto et al. 2009; Valente et al. 2010). Understanding

115 the genetic modifiers and environmental contribution underlying the phenotypic variation

116 will be key to understanding disease etiology as will understanding when and how

117 relevant pathways interact. In mouse models of the JSRD- and Meckel Syndrome-linked

118 gene Tmem67, two phenotypic categories emerged: one with cerebellar malformations

119 resembling JSRD and another with more severe CNS defects reminiscent of Meckel

120 syndrome (Abdelhamed et al. 2013). The two categories correlated with whether cilia

121 were retained, with the severe Meckel-like phenotype observed in animals lacking cilia.

122 Furthermore, the two phenotypic groups impacted Hh and Wnt signaling differently,

123 pointing to both pathways being critical (Abdelhamed et al. 2019). Importantly, it is not

124 simply whether cilia are present, as another JSRD mouse model, Talpid3, lacks cilia yet

125 displays a JSRD-like small cerebellar vermis (Bashford and Subramanian 2019). Thus,

126 mouse models are incredibly informative yet point to the enormous complexity

127 underlying the MTS.

128 Here we investigate the role of ARL13B in relation to Hh signaling in two major

129 features of the MTS: targeting of the SCPs to the thalamus and hypoplasia of the

130 cerebellar vermis. We explore these processes using a series of mouse alleles through

131 which we first define the roles of Hh signaling and ARL13B in SCP projections.

132 Subsequently, we untangle the role of ARL13B from within and outside of the cilium and

133 investigate a JS-causing patient allele. Taken together, our data illuminate the roles of

134 ARL13B in MTS etiology and the complexity in modeling aspects of the MTS in mouse. 


\section{MATERIALS \& METHODS}

137

Mouse lines

All mice were cared for in accordance with NIH guidelines and Emory University's Institutional Animal Care and Use Committee (IACUC). Lines used were Nex-Cre (C3H-HeJ-Neurod6 $\left.{ }^{\text {tm1(cre)Kan }}\right)$ [MGl:2668659], Brn4-Cre (C3H/HeJ-Tg(Pou3f4cre)32Cren) [MGI:2158470], Smo ${ }^{\text {flox }}\left(\mathrm{C} 3 \mathrm{H} / \mathrm{HeJ}-\mathrm{Smo}^{\text {tm2AMC }}\right.$ [MGI:2176256], Arl13b $b^{\text {flox }}$

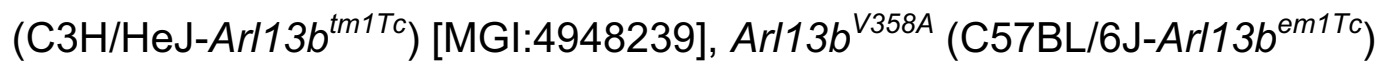
[MGI:6256969], and $A r 113 b^{R 79 Q}$ (C57BL/6J-Arl13b $b^{e m 2 T c}$ ) [MGI:6279301]. Note that $A r l 13 b^{4}$ is the deletion allele resulting from germline deletion of the conditional $A r l 13 b^{\text {flox }}$ allele. Genotyping was as previously described (Heydemann et al. 2001; Goebbels et al. 2006; Nolan-Stevaux et al. 2009; Su et al. 2012; Gigante et al. 2020).

To generate the R79Q mutation in Arl13b, a CRISPR gRNA (ATTATTATGCTGAATCCTATGG; PAM sequence is italicized) targeting exon 3 of the Arl13b locus along with a 180bp donor oligo (5'-CTCCCACTGTTGGCTTTTCTAAAATTGATCTGAGACAAGGAAAGTTCCAAGTTACCATCTTTGACTTAGGAGGTGGAAAA AGAATTCÁGGGㅡAAㅗGGAAGAATTATTATGCTGAATCCTATGGGGTAATATTTGTT GTGGATTCCAGTGATGAGGAGAGAATGGAAGAAACAAAGGAGA-3'; underlined bases are engineered) were designed to generate a G-to-A change creating the R79Q point mutation as well as A-to-C and T-to-A silent changes to create a Ndel restriction site that could be used for genotyping (Millipore Sigma). The gRNA (50 ng/ul), ssDNA oligo donor (50 ng/ul) and wild type Cas9 mRNA (10 ng/ul) were injected into 1-cell C57BL/6J zygotes and subsequently transplanted at the 2-cell stage into C57BL/6J pseudopregnant females by the Emory Transgenic and Gene Targeting Core; all 
159 reagents were purchased from Millipore Sigma. Genomic DNA from toes was amplified

160 via PCR using primers (5'-TCACTTGCAACAGAGCATCC-3') and (5'-

161 ACAGCTCTGCCCGTGTTTAC-3') located upstream and downstream of the donor oligo

162 breakpoints; products were sequenced with the forward (first) primer. A single founder

163 animal heterozygous for both the R79Q mutation and Ndel restriction site was identified

164 with no additional editing. Subsequent allele-specific genotyping of progeny was

165 performed on ear punch or yolk sac using the following primers: Fwd-wt primer: 5'-

166 GGAGGTGGAAAAAGAATaCg-3'; Fwd-mut primer: 5'-

167 gctctatggctgGGAGGTGGAAAAAGAATTga-3'; Rev primer: 5'-

168 AGTGCTAAGACACCCGAGGA-3'. PCR bands at 142bp (wild type) and/or 154bp

169 (mutant) were produced, due to the addition of 12 non-templated bases to the 5 ' end of

170 the Fwd-mut primer (lowercase). Note the 3' ends of the two forward primers differed in

171 the base that codes for the $\mathrm{R}$ to $\mathrm{Q}$ change (final nucleotide of the primer) and includes a

172 "wobble" base (lowercase) to provide allele-specific amplification after the first round of

173 PCR (Gaudet et al. 2009). In order to breed away any potential off-target edits, the

174 founder was backcrossed to C57BL/6J for three generations with at least two

175 independent meiotic opportunities for recombination in each generation.

177 Tract tracing injections and analysis

$178 \quad$ Tract tracing experiments were performed according to a protocol approved by

179 Emory University's Institutional Animal Care and Use Committee (IACUC). Male and

180 female mice at postnatal day 90 or older were used for tract tracing experiments. At

181 least 3 mice of each genotypic group were analyzed in experiments (exact $\mathrm{N}$ included in 
182 Figures 1-3, S1). Mice were anesthetized with inhaled isoflurane and maintained under

183 anesthesia throughout the procedure. Animals were secured in the stereotax, and the

184 scalp was opened with bregma and lambda aligned to flatskull position. Dorsal thalamus

185 injections were targeted to the bregma (AP:-0.70, ML:+1.13, DV:-3.28, Angle:0) and

186 ventral thalamus injections were targeted using coordinates to the bregma (AP:-0.70,

187 ML:-3.11, DV:-4.69, Angle:25 $)$. Ventral injection targeting includes a $25^{\circ}$ angle to avoid

188 pulling dye through the dorsal thalamus upon needle removal. Then, a 5 ul Hamilton

189 microsyringe was lowered to target and target was injected with lysine fixable dextran

190 tetramethylrhodamine neuroanatomical tracer (fluoro-Ruby, 10,000 MW, ThermoFisher

191 Scientific D1817). Animals received $0.05-0.5$ ul injections of $10 \%$ dextran

192 tetramethylrhodamine in sterile phosphate buffered saline (PBS, $\mathrm{pH}=7.25)$ unilaterally

193 at a rate of $0.1 \mathrm{ul} / \mathrm{minute}$. The $0.5 \mathrm{ul}$ injection volume initially used resulted in high

194 background (non-specific) fluorescence. Later surgeries were conducted with 0.05 ul of

195 dye, which resulted in lower background and retention of a strong signal in the DCN.

196 Seven days post-procedure, mice were perfused with 50mls of PBS followed by

$19730 \mathrm{mls}$ of $4 \%$ paraformaldehyde (PFA). Brains were kept in PFA overnight and

198 subsequently placed in $30 \%$ sucrose in $0.1 \mathrm{M}$ phosphate buffer $(\mathrm{pH} 7.3)$ for

199 cryoprotection for at least 48 hours. Brains were embedded in Tissue-Tek OCT

200 compound (Sakura) for coronal cryostat sectioning. Sections were 60 microns thick and

201 processed through $70 \%$ ethanol dehydration and $0.1 \%$ sudan black autofluorescence

202 quencher, rehydrated in PBS and treated with DAPI to stain nuclei prior to fluorescence

203 imaging. Images were taken on a Lionheart FX automated microscope (Biotek) or at 5x

204 magnification on a Leica DM6000B microscope (Leica) using SimplePCl imaging 
205 software (Hamamatsu). The Leica images were subsequently stitched together to reveal

206 the entirety of the brain section in Fiji (Schindelin et al. 2012) or Photoshop (Adobe).

207 Surgical injection sites were assessed to ensure dye was present at the desired

208 injection site. If the injection was off-target or dye at the injection site was not seen,

209 samples were removed from analysis. Cerebellar images from injections were evaluated

210 for DCN staining with assessor blinded to genotype. The number of injections that

211 resulted in fluorescent DCN for each injection site (dorsal and ventral thalamus) were

212 compared between mutant and control genotypes using a two-sided Fisher's exact test

213 (PRISM 8.2.0).

215 Phenotypic analysis of embryos

216 Timed matings of mice were performed to generate somite-matched embryos at

217 embryonic day 10.5 (E10.5). Embryos were dissected in cold PBS and processed for

218 immunofluorescence staining as previously described (Constable et al. 2020). Primary

219 antibodies used were: mouse anti-Shh (5E1, 1:10), mouse anti-Pax6 (PAX6, 1:100)

220 (Developmental Studies Hybridoma Bank), rabbit anti-Olig2 (AB9610, 1:500, Millipore

221 Sigma), and mouse anti-Arl13b (N295B/66, 1:1500, NeuroMab). Multiple sections from

222 three embryos of each genotype were examined.

\section{Analysis of anatomical measures}

Weanling age (P20-P24) male and female mice were sacrificed and brains were

226 harvested and fixed in 4\% PFA overnight at $4^{\circ}$. Ten sex-matched pairs of mouse brains

227 were collected for each genotype; control animals were either wild type or heterozygous 
228 for the $A r l 13 b$ point mutation or floxed allele (so $A r l 13 b^{R 79 Q /+}, A r l 13 b^{V 358 A /+}$ or $A r l 13 b^{f l o x /+}$ )

229 or lacked Brn4-Cre (for Arl13 $b^{\text {Brn4-Cre }}$ ). Brains were imaged on a tilted stage to present a

230 surface view of the cerebellum, with a standard ruler in frame to confirm scale, using a

231 dissecting microscope (Leica MZFLIII). Measurements were made in FIJI (Schindelin et

232 al. 2012) with the investigator blind to genotype. Whole cerebellar width was measured

233 at the widest part of the cerebellum, coinciding with lobule $\mathrm{Cl}$ or Cll. Vermis width was

234 calculated by measuring the widest part of lobule VII (Deshpande et al. 2020).

235 Hemisphere and vermis heights were measured at the longest rostro-caudal point of the

236 hemisphere or at the midline of the vermis (see Figure 5). Body and brain weights were

237 measured on a standard lab scale. For each sex- and age-matched pair, the ratio of

238 mutant to control measures were calculated and graphed. A one-sample t-test was

239 performed after transforming the ratio data to a $\log (2)$ scale to normalize data

240 distribution (PRISM 8.2.0). Using the vermis width measures from our control brains

$241($ mean $=2.6 \mathrm{~mm}, \mathrm{SD}=0.18)$, a power calculation for a one-sided t-test estimated $90 \%$

242 power to detect a $10 \%$ difference with $9-10$ paired samples for a nominal alpha=0.05

243 (https://clincalc.com/stats/samplesize.aspx and

244 https://www.stat.ubc.ca/ rollin/stats/ssize/n2.html).

Data availability

Mouse lines are available upon request. Supplemental material available at

248 figshare. Figure S1 contains diagrams illustrating the complete results of the injection

249 and tract tracing experiments. Figure S2 contains a schematic of the CRISPR strategy. 
250 The authors affirm that all data necessary for confirming the conclusions of the article

251 are present within the article and figures.

\section{RESULTS}

SMO is required for normal SCP projection to the dorsal thalamus

In order to test whether proper projection of SCPs requires Hh signaling, we compared the SCP tracts in mice in which we deleted the gene encoding the obligate Hh transducer, Smoothened (Smo), to control animals. As Smo null embryos die during embryogenesis, we deleted Smo specifically in the projection neurons by generating Nex-Cre;Smo ${ }^{f l f l}$ mice, which we refer to as Smo ${ }^{\text {Nex-Cre }}$ (Zhang et al. 2001; Caspary et al.

260 2002). Nex-Cre initiates CRE recombinase expression at E11.5, as the precursor cells

261 of the deep cerebellar nuclei (DCN) begin to migrate and become specified (Fink et al.

262 2006; Goebbels et al. 2006). In the mature cerebellum, the SCPs project rostrally from

263 the DCN (illustrated in Figure 1A). After entering the midbrain, the SCPs cross the

264 midline and again turn rostrally to project to two positions in the rostral thalamus: one

265 tract takes a slight dorsal path and the other tract remains in the same plane; for

266 simplicity here, we term these projection sites the dorsal and ventral thalamus,

267 respectively (Bohne et al. 2019). To examine the SCP tracts, we used retrograde tract

268 tracing in which we performed stereotaxic injections of a lipophilic dextran dye into

269 either the dorsal (Figure 1B) or ventral (Figure 1C) thalamus and allowed the dye to

270 diffuse through the axons to the associated neuron's cell body ( $\sim 7$ days); we then

271 sacrificed the animal and examined the cerebellum for evidence of the lipophilic dye

272 indicating tracing. 
We found that both dorsal and ventral thalamus injections resulted in visible

274 clusters of dye-stained cells in the contralateral DCN, and not the ipsilateral DCN, in

275 control animals indicating the retrograde tract tracing reliably labelled the SCPs in our

276 hands (Figures 1D-E, S1A-B, dorsal: 6/8; ventral: 8/11). In the Smo ${ }^{\text {Nex-Cre }}$ mice, the

277 results differed depending on whether we injected in the dorsal or ventral thalamus

278 (Figures 1F-G, S1C-D). In the ventral thalamus injections, we detected dye-stained

279 clusters of cells in the contralateral DCN but not the ipsilateral DCN, indicating normal

280 SCP projection to the ventral thalamus (Figure 1G, 4/4 injections). This indicates that at

281 least some SCPs cross the midline. In the dorsal thalamus injections, we could not

282 detect dye-stained clusters of cells in either the contralateral or ipsilateral DCN (Figure

283 1F, 0/6 injections) suggesting that SCPs lacking SMO do not project to the dorsal

284 thalamus. These data implicate SMO as critical for proper projection of the SCPs to the

285 dorsal thalamus.

$A R L 13 B$ is required for normal SCP projection to the dorsal thalamus

next assessed ARL13B's role in proper SCP projection. In order to delete ARL13B

290 specifically in projection neurons, we generated Nex-Cre;Arl13b $b^{f / f l}$ mice, which we refer

291 to as $A r l 13 b^{\text {Nex-Cre }}$. We performed dorsal and ventral thalamus injections for retrograde

292 tract tracing to examine the SCPs (Figures 1H-I, S1C-D). In the ventral thalamus

293 injections of $A r 113 b^{\text {Nex-Cre }}$ mice, we found dye-stained clusters of cells in the

294 contralateral DCN consistent with normal SCP projections crossing the midline and

295 projecting to the ventral thalamus (Figure 1I, 4/4 injections). In contrast, in the dorsal 
296 thalamus injections of $A r l 13 b^{\text {Nex-Cre }}$ mice, we generally did not detect dye-stained

297 clusters of cells in either the contralateral or ipsilateral DCN, suggesting that the SCPs

298 lacking ARL13B do not project to the dorsal thalamus (Figure $1 \mathrm{H}, 1 / 7$ injections). These

299 data link ARL13B function to normal SCP projection. Furthermore, they reveal a similar

300 phenotype in $S m o^{\text {Nex-Cre }}$ and $A r l 13 b^{\text {Nex-Cre }}$ mice.

301

302

ARL13B does not function from within cilia to mediate SCP guidance

$A R L 13 B$ and the other 35 genes implicated in Joubert syndrome associate with

304 the cilium or centrosome leading to the assumption that protein dysfunction from these

305 locales underlies JSRD phenotypes (Parisi 2019). To directly ask whether ARL13B

306 mediates SCP guidance to the dorsal thalamus from within cilia, we examined a mouse

307 expressing a cilia-excluded variant of ARL13B, ARL13B ${ }^{\mathrm{V} 358 \mathrm{~A}}$ (Figure 2) (Gigante et al.

308 2020). We previously demonstrated that $A R L 13 B^{V 358 A}$ retains all known ARL13B

309 biochemical activity, is undetectable in cilia yet transduces vertebrate Hh signaling

310 normally (Mariani et al. 2016; Gigante et al. 2020). We found that either dorsal or ventral

311 thalamus injections resulted in visible clusters of dye-stained cells in the contralateral

312 DCN in control (Figures 2A-B, S1G-H, dorsal: 3/3; ventral: 4/4) and Arl13b ${ }^{\text {V358A/V358A }}$

313 (Figure 2C-D, dorsal: 4/4; ventral: 3/3) animals. In the context of the previous result

314 showing that $A r l 13 b^{\text {Nex-Cre }}$ mice display abnormal SCP projections to the dorsal

315 thalamus, these data demonstrate that ARL13B does not function from within cilia to 316 regulate SCP projections.

318 SCP projection is normal in mice expressing a Joubert-causing allele, Arl13b ${ }^{\mathrm{R} 79 \mathrm{Q}}$ 

Joubert syndrome, we generated a mouse expressing the JSRD-causing R79Q

321 mutation (Figure 3A). We used CRISPR/Cas9 editing to change the conserved residue

322 in the mouse genome (Figures 3B, S2). This amino acid change disrupts ARL13B's

323 GEF activity for ARL3 (Gotthardt et al. 2015; Ivanova et al. 2017). We found

$324 A r l 13 b^{R 79 Q / R 79 Q}$ mice were viable and fertile. We bred the $A r l 13 b^{R 79 Q}$ allele to the null

$325 A r l 13 b^{\Delta}$ allele to make $A r l 13 b^{R 79 Q / A}$ animals, which we found survived to adulthood. As

$326 A r l 13 b^{\Delta / \Delta}$ are embryonic lethal, this genetically demonstrates that $A r l 13 b^{R 79 Q}$ is a

327 hypomorphic allele of $A R L 13 B$ (Su et al. 2012).

To assess the role of $A R L 13 B^{R 79 Q}$ in SCP guidance, we performed dorsal and

329 ventral thalamus dye injections in control and $A r l 13 b^{R 79 Q / R 79 Q}$ mice. We identified visible

330 clusters of dye-stained cells in the contralateral DCN in control (Figures 3C-D, S1E-F,

331 dorsal: 4/4; ventral: 3/3) and $A r l 13 b^{R 79 Q / R 79 Q}$ (Figure 3E-F, dorsal: 3/3; ventral: 3/4)

332 animals. Thus, despite the constitutive expression of the JSRD-causing allele

333 throughout development, we did not detect a SCP projection defect in the

$334 A r l 13 b^{R 79 Q / R 79 Q}$ mouse model. In the context of the abnormal SCP projections to the

335 dorsal thalamus that we identified in the $S m o^{\text {Nex-Cre }}$ and $A r l 13 b^{\text {Nex-Cre }}$ mice, this result

336 indicates that the $A r l 13 b^{R 79 Q}$ allele does not disrupt SMO function or any ARL13B

337 function that regulates SMO.

339 Arl13b $b^{R 79 Q / R 79 Q}$ mice display normal Shh signal transduction in neural tube patterning

340 To further investigate the role of the $A r l 13 b^{R 79 Q}$ allele in Hh signaling, we

341 examined embryonic neural patterning as it is exquisitely sensitive to alterations in Shh 
342 activity (Chiang et al. 1996; Briscoe and Ericson 1999). We generated E10.5 embryos

343 and stained neural tube sections with antibodies against Shh, Olig2 and Pax6 (Figure

344 4). As expected in wild type embryos, we observed Shh expression in the ventral-most

345 cells (the floorplate), Olig2 expression in lateral cells and Pax6 expression dorsally. We

346 also saw the established abnormal cell fates in null $A r l 13 b^{N \Delta}$ embryos: loss of Shh

347 staining in the floorplate (Figure 4D), dorsal and ventral expansion of Olig2 expression

348 (Figure 4H), and a dorsal shift in Pax6 expression (Figure 4L) (Su et al. 2012). We

349 found both $A r 113 b^{R 79 Q / R 79 Q}$ (Figure 4B, F, J) and $A r l 13 b^{R 79 Q / 4}$ (Figure 4C, G, K) embryos

350 displayed neural patterning indistinguishable from wild type embryos, indicating the

$351 A r l 13 b^{R 79 Q}$ allele is not dosage-sensitive and does not disrupt Shh signaling in

352 determining neural cell fate. In addition, $A R L 13 B^{R 79 Q}$ protein localized to cilia (Figure

353 4N), consistent with previous results (Li et al. 2010; Humbert et al. 2012; Li et al. 2016;

354 Mariani et al. 2016).

355

Arl13b $b^{R 79 Q / R 79 Q}$ mice display normal cerebellar width

The lack of a SCP projection phenotype in the $A r l 13 b^{R 79 Q / R 79 Q}$ mice surprised us

358 since JS patients display the MTS. In addition to defects in the SCPs, the MTS is due to

359 an underdeveloped cerebellar vermis, so we examined the width of the cerebellum and

360 the cerebellar vermis (Figure 5) (Aguilar et al. 2012). To quantify cerebellar width, we

361 performed analysis of surface-facing anatomical measurements validated to be

362 sufficiently sensitive to detect small differences in vermis width (Deshpande et al. 2020).

363 Briefly, we measured cerebellar width as well as cerebellar vermis width (widest part of

364 lobule VII) of fixed whole mount dissected brains. For each sex- and age-matched pair, 
365 we calculated the ratio of the width measurements from mutant to control, which we

366 compared to a hypothetical value of 1 (indicating no difference between groups). We

367 detected no differences in the overall cerebellar width or the cerebellar vermis width

368 between control and $A r l 13 b^{R 79 Q / R 79 Q}$ mice of either sex (Figure 5B). Furthermore, we

369 found no difference in body or brain weight for $A r l 13 b^{R 79 Q / R 79 Q}$ mutants compared to

370 controls (Figure 5B). Thus, unlike patients carrying $A R L 13 B^{R 79 Q / R 79 Q}, A r l 13 b^{R 79 Q / R 79 Q}$

371 mice do not display a detectable growth deficit in the cerebellar vermis.

Global cerebellar hypoplasia is observed in mice lacking Ar13b in all neurons

Cerebellar size is well established to be regulated, in part, via Shh signaling

which controls proliferation of the cerebellar granule precursor cells (Kenney and

376 Rowitch 2000; Chizhikov et al. 2007). In order to better understand the vermis

377 hypoplasia phenotype seen in JBTS patients in relation to ARL13B, we wanted to

378 investigate how ARL13B regulates cerebellar width. To do so, we crossed the Brn4-Cre

379 allele into the conditional null $A r l 13 b^{f l / f l}$ background, called Arl13b $b^{\text {Brn4-Cre }}$ (Figure 6). Brn4-

380 Cre initiates expression at E8.5 throughout the neuroectoderm so the cerebellum

381 develops in the absence of ARL13B (Heydemann et al. 2001; Hazen et al. 2012). We

382 again calculated width ratios using surface-facing anatomical measurements and found

383 the overall width of the cerebellum was $6 \%$ reduced in both females and males lacking

384 ARL13B compared to control littermates at weaning (Figure 6B, $p<0.1$ ). More striking, in

385 the cerebellar vermis we detected a $27 \%$ reduction in width in female and a $33 \%$

386 reduction in male mutants compared to controls (Figure 6B, $\mathrm{p}<0.0001) . A r l 13 b^{\text {Brn4-Cre }}$

387 mice develop hydrocephaly just after weaning which often leads to death. This is 
388 reflected in the body and brain weight ratios: while the mutant mice had slightly lower

389 body weights, they had comparatively heavier brains (Figure 6B). From these data, we

390 conclude that loss of $A R L 13 B$ leads to a modest global cerebellar width deficit and a

391 more pronounced cerebellar vermis width reduction.

Arl13b ${ }^{\text {V358A/V358A }}$ mice display normal cerebellar width

JS is classified as a ciliopathy due to the majority of causative genes encoding proteins that, like ARL13B, are associated with cilia. In order to better understand the role of ciliary ARL13B in cerebellar size, we examined cerebellar width in the mice expressing the cilia-excluded variant $A R L 13 B^{\mathrm{V} 358 \mathrm{~A}}$ (Figure 7) (Gigante et al. 2020). We

398 detected no difference in the overall cerebellar width or that of the cerebellar vermis between control and $A r 113 b^{V 358 A / V 358 A}$ mice (Figure 7B). Thus, ARL13B does not control

400 cerebellar width from within cilia.

\section{DISCUSSION}

Here we demonstrate that complete loss of $A r l 13 b$ function in mouse can account

404 for two aspects of the MTS: aberrant SCP thalamic targeting and cerebellar vermis

405 hypoplasia. We expand the role of Hh signaling as a critical guidance cue by showing it

406 is required for proper SCP projection to the dorsal thalamus. Our finding that the SCP

407 phenotype is similar in $S m o^{N e x-C r e}$ and $A r l 13 b^{\text {Nex-Cre }}$ mice is consistent with a model

408 whereby ARL13B regulates SCP projections to the dorsal thalamus via a SMO-

409 dependent mechanism. In line with previous work showing that ARL13B does not

410 function from within cilia to regulate Shh-guided axon guidance, we found normal SCP 
411 thalamic targeting in mice expressing only a cilia-excluded ARL13B variant (Ferent et al.

412 2019). By mutating a conserved arginine to glutamine, we generated a mouse

413 expressing a mutation linked to JSRD in humans and observed no change in vertebrate

414 Hh signaling (Cantagrel et al. 2008). Additionally, we identified no defects in

$415 A r l 13 b^{R 79 Q / R 79 Q}$ SCP projections. Whereas complete ARL13B deletion $\left(A r l 13 b^{\text {Brn4-Cre }}\right)$ in

416 the cerebellum led to global hypoplasia, we show the cerebellum of $A r l 13 b^{R 79 Q / R 79 Q}$ mice

417 is not significantly different in width compared to controls.

418 Overall, our data indicate ARL13B function is critical for both SCP targeting and

419 controlling cerebellar vermis width. At one level, our data implicate Hh signaling in the

420 etiology of the MTS since we show that SCP targeting requires SMO. However, at

421 another level, our data indicate that Hh-independent pathways are at play as we don't

422 observe Hh-dependent neural tube patterning defects in the presence of the JSRD-

423 causing $A r l 13 b^{R 79 Q}$ allele. In other mouse models of JSRD where the hypoplasia is

424 specific to the cerebellar vermis, Wnt signaling is affected (Lancaster et al. 2011). Thus,

425 the MTS could be due to disruption of different pathways in the SCPs and the vermis.

426 This would imply that the 35 JSRD implicated genes all affect the distinct pathways in a

427 similar manner (Parisi 2019). Alternatively, the MTS may form due to alterations in any

428 of a few pathways - and it is even possible that alterations in one pathway could impact

429 other pathways - or the ability of cells to respond to those other pathways. Such a

430 model is hinted at by previous work showing interplay between the Hh and Wnt

431 pathways underlying the severity of hindbrain phenotypes (Hagemann and Scholpp

432 2012; Bashford and Subramanian 2019). While we haven't detected any changes in

433 Wnt response in the absence of ARL13B function, we may have not examined the 
434 relevant biological process or used a sensitive enough readout (Horner and Caspary

435 2011). Parallel reasoning would thus suggest that while $A r l 13 b^{R 79 Q / R 79 Q}$ mice clearly

436 transduce Hh reasonably well, there may be subtle changes in Shh signaling or

437 changes that influence Wnt signaling. Our data are consistent with the complexity

438 exhibited by other JSRD mouse models examined to date (Delous et al. 2007; Garcia-

439 Gonzalo et al. 2011; Roberson et al. 2015; Bashford and Subramanian 2019).

441 observed in the mice. Available methods for live-imaging and examination of post-

442 mortem tissues suggest a range of SCP decussation defects, with some tracts

443 appearing thickened on the ipsilateral side relative to their DCN (Yachnis and Rorke

444 1999; Poretti et al. 2007). Surprisingly, in the mutant mice we infer midline crossing of

445 the SCPs. In the case of the Smo ${ }^{N e x-C r e}$ conditional mice, it is formally possible that the

446 SCPs do not rely on SMO for midline crossing but only for subsequent targeting to the

447 dorsal thalamus. The fact that the $A r l 13 b^{\text {Nex-Cre }}$ conditional mice display a highly similar

448 phenotype to the Smo ${ }^{\mathrm{Nex}-\mathrm{Cre}}$ conditional mice makes this less likely, since ARL13B is

449 directly implicated in JSRD and regulates SMO-dependent axon guidance in other

450 contexts (Cantagrel et al. 2008; Ferent et al. 2019). It is also plausible that the protein

451 turnover driven by Nex-Cre completed after midline crossing occurred. Nex-Cre

452 expression initiates at E11.5 in the cells on the rhombic lip of the cerebellar anlage as

453 they start to migrate and be specified before occupying the deep cerebellar nuclei (Fink

454 et al. 2006; Goebbels et al. 2006). We expect deletion would occur in the precursors

455 and therefore the neurons of the DCN would not express protein. Finally, it is possible

456 that the mouse is not a valid system in which to model the SCP midline crossing defect. 
457 This might explain why we saw no defects in the SCP targeting of the $A r l 13 b^{R 79 Q / R 79 Q}$

458 mice, as this is a constitutive mutation that requires no protein turnover, yet

459 homozygous expression of $A R L 13 B^{R 79 Q}$ in patients results in the molar tooth sign, which

460 has been associated with failed decussation of white matter tracts (Quisling et al. 1999).

461 Indeed, other mouse mutants such as Cep290 and Ahi1 which recapitulate the

462 cerebellar vermis hypoplasia, also do not display midline crossing defects in the SCPs

463 (Lancaster et al. 2011). Whether this is due to anatomical distinctions between the

464 cerebellum in mouse and human or the genetic background on which these models

465 were examined are open questions. Recent work highlights clear molecular and

466 temporal differences between mouse and human cerebellar development (Haldipur et

467 al. 2019; Behesti et al. 2021).

468 Examining SCP projections is labor intensive and it has not been done

469 systematically among the JSRD mouse models (Bashford and Subramanian 2019; Guo

470 et al. 2019). While previous work showed that $A r l 13 b^{\text {Nex-Cre }}$ and Inpp5e $e^{\text {Nex-Cre }}$ mice

471 exhibit SCP targeting deficits, here we pinpoint the Arl13b $b^{\text {Nex-Cre }}$ defect as specific to the

472 projection to the dorsal thalamus (Guo et al. 2019). The projection to the ventral

473 thalamus remains intact, suggesting there is not a generalized deficit in axon outgrowth

474 within the tract. The work on the Arl13b $b^{\text {Nex-Cre }}$ and Inpp5e $e^{\text {Nex-Cre }}$ SCP targeting deficits

475 argue that PI3K/Akt signaling from within cilia led to the tract defects (Guo et al. 2019).

476 However, we found that cilia-excluded ARL13B mediated SCP targeting normally.

477 These conflicting results could be explained by differences in the experimental details

478 as the data supporting ciliary ARL13B function used a human ARL13B viral expression

479 construct to rescue conditionally-deleted mice whereas we used genetic mutations 
480 engineered at the endogenous locus in this study. Alternatively, these data could

481 indicate that ARL13B plays an important cellular role in the ciliary trafficking of key

482 components needed for the PI3K/Akt pathways.

483 JSRD-causing mutations in ARL13B are generally restricted to the GTPase

484 domain of the protein, although two residues outside that domain are implicated in

485 disease (Cantagrel et al. 2008; Bachmann-Gagescu et al. 2015; Thomas et al. 2015;

486 Shaheen et al. 2016; Rafiullah et al. 2017). Based on other ARL proteins, ARL13B likely

487 assumes distinct conformations upon the binding either GDP or GTP, permitting

488 different binding partners or altering affinities for binding partners (Pasqualato et al.

489 2002; Miertzschke et al. 2014). None of the tested JSRD-causing mutations (R79Q,

490 Y86C or R200C) disrupt GTP binding or hydrolysis, however, all three mutations disrupt

491 ARL13B function as an ARL3 GEF (Ivanova et al. 2017). The arginine at this position is

492 located within the Switch 2 region of ARL13B and is conserved in humans, mice,

493 zebrafish and Chlamydomonas (Figure 3B). We were surprised that we were unable to

494 detect any defects in our mouse, as we expected to model some aspect of Joubert

495 syndrome. Humans with homozygous R79Q mutation exhibit motor and ocular defects

496 (among other symptoms), whereas arl13b-null zebrafish injected with human ARL13B-

497 R79Q mRNA only partially rescue the ciliopathy phenotypes of curved body axis and

498 cystic kidney (Cantagrel et al. 2008). These species-dependent differences emphasize

499 the importance of analyzing mutations expressed from the endogenous promoter over

500 the course of normal development. A recent study linked arl13b disruption during

501 zebrafish development to reduced granule and Purkinje cells through a down-regulation

502 of Wnt signaling (Zhu et al. 2020). Given that complete deletion of ARL13B impacts 
503 broader biological processes in the cerebellum than the R79Q mutation and that the null

504 mutant misregulates Hh signaling whereas R79Q does not, we conclude that a subset

505 of ARL13B function is disrupted in JSRD.

506

507 Acknowledgements

508 We are grateful to L. Mariani for her initial work on this project, R.E. Van Sciver and E.

509 Gigante for critical comments on the manuscript and J.G. Mulle for the statistical

510 consults.

511

\section{$512 \quad$ Funding}

513 This work was supported by funding from National Institutes of Health grants

514 R01NS090029, R01GM110663 and R35GM122549 to T.C. and T32GM008490 and

515 F31NS101806 to S.K.S. with additional support from the Emory University Integrated

516 Cellular Imaging Microscopy Core of the Emory Neuroscience NINDS Core Facilities

517 grant, P30NS055077. This study was supported in part by the Mouse Transgenic and

518 Gene Targeting Core (TMF), which is subsidized by the Emory university School of

519 Medicine and is one of the Emory Integrated Core Facilities. Additional support was

520 provided by the National Center for Advancing Translational Sciences of the National

521 Institutes of Health under Award Number UL1TR000454. The content is solely the

522 responsibility of the authors and does not necessarily reflect the official views of the

523 National Institutes of Health

\section{Conflicts of Interest}


526 The authors have no competing interests to declare.

\section{Author contributions statement}

529 Author Contributions: Conceptualization T.C.; Methodology S.K.S. and A.B.L.;

530 Validation S.K.S. and A.B.L; Formal Analysis S.K.S. and A.B.L.; Investigation S.K.S.

531 and A.B.L.; Writing - Original Draft S.K.S. and T.C.; Writing - Review \& Editing S.K.S.,

532 A.B.L. and T.C.; Visualization S.K.S. and A.B.L.; Supervision T.C.; Project

533 Administration T.C.; Funding Acquisition T.C.

\section{References}

536 Abdelhamed, Z. A., D. I. Abdelmottaleb, M. E. El-Asrag, S. Natarajan, G. Wheway et al., 2019 The ciliary Frizzled-like receptor Tmem67 regulates canonical Wwnt/betacatenin signalling in the developing cerebellum via Hoxb5. Sci Rep. 9: 5446. doi:10.1038/s41598-019-41940-5

Abdelhamed, Z. A., G. Wheway, K. Szymanska, S. Natarajan, C. Toomes et al., 2013 human samples reveals impaired SHH-dependent cerebellar development in Variable expressivity of ciliopathy neurological phenotypes that encompass Meckel-Gruber syndrome and Joubert syndrome is caused by complex deregulated ciliogenesis, Shh and Wnt signalling defects. Hum Mol Genet. 22: Joubert syndrome/Meckel syndrome. Proc Natl Acad Sci U S A. 109: 1695116956. doi:10.1073/pnas.1201408109 
Alkanderi, S., E. Molinari, R. Shaheen, Y. Elmaghloob, L. A. Stephen et al., 2018 ARL3 mutations cause Joubert syndrome by disrupting ciliary protein composition. Am J Hum Genet. 103: 612-620. doi:10.1016/j.ajhg.2018.08.015

Arts, H. H., D. Doherty, S. E. C van Beersum, M. A. Parisi, S. J. F. Letteboer et al., 2007 Mutations in the gene encoding the basal body protein RPGRIP1L, a nephrocystin-4 interactor, cause Joubert syndrome. Nat Genet. 39: 882-888. doi:10.1038/ng2069

Asadollahi, R., J. E. Strauss, M. Zenker, O. Beuing, S. Edvardson et al., 2018 Clinical and experimental evidence suggest a link between KIF7 and C5orf42-related ciliopathies through Sonic Hedgehog signaling. Eur J Hum Genet. 26: 197-209. doi:10.1038/s41431-017-0019-9

Bachmann-Gagescu, R., J. C. Dempsey, I. G. Phelps, B. J. O'Roak, D. M. Knutzen et al., 2015 Joubert syndrome: A model for untangling recessive disorders with extreme genetic heterogeneity. J Med Genet. 52: 514-522. doi:10.1136/jmedgenet-2015-103087

Bachmann-Gagescu, R., J. C. Dempsey, S. Bulgheroni, M. L. Chen, S. D’Arrigo et al., 2020 Healthcare recommendations for Joubert syndrome. Am J Med Genet A. 182: 229-249. doi:10.1002/ajmg.a.61399

Bashford, A. L., and V. Subramanian, 2019 Mice with a conditional deletion of Talpid3 (KIAA0586) - a model for Joubert syndrome. J Pathol. 248: 396-408. doi:10.1002/path.5271

Bay, S.N., A. B. Long, and T. Caspary, 2018 Disruption of the ciliary GTPpase Arl13b suppresses Sonic hedgehog overactivation and inhibits medulloblastoma 
formation. Proc Natl Acad Sci U S A. 115: 1570-1575.

doi:10.1073/pnas.1706977115

Behesti, H. A. Kocabas, D. E. Buchholz, T. S. Carroll, and M. E. Hatten, 2021 Altered temporal sequence of transcriptional regulators in the generation of human cerebellar granule cells. bioRxiv. doi:10.1101/2021.01.17.427030 (Preprint posted January 17, 2021).

Bielas, S. L., J. L. Silhavy, F. Brancati, M. V. Kisseleva, L. Al-Gazali et al., 2009 Mutations in INPP5E, encoding inositol polyphosphate-5-phosphatase E, link phosphatidyl inositol signaling to the ciliopathies. Nat Genet. 41: 1032-1036.

Bimonte, S., A. De Angelis, L. Quagliata, F. Giusti, R. Tammaro et al., 2011 Ofd1 is required in limb bud patterning and endochondral bone development. Dev Biol. 349: 179-191. doi:10.1016/j.ydbio.2010.09.020

Bohne, P., M. K. Schwarz, S. Herlitze, and M. D. Mark, 2019 A new projection from the deep cerebellar nuclei to the hippocampus via the ventrolateral and laterodorsal

Brancati, F., B. Dallapiccola, and E. M. Valente, 2010 Joubert syndrome and related disorders. Orphanet J Rare Dis. 5: 20. doi:10.1186/1750-1172-5-20 
594 Briscoe, J., and J. Ericson J, 1999 The specification of neuronal identity by graded

595 Sonic Hedgehog signalling. Semin Cell Dev Biol. 10: 353-362. doi:10.1006/scdb.1999.0295

Cantagrel, V., J. L. Silhavy, S. L. Bielas, D. Swistun, S. E. Marsh et al., 2008 Mutations in the cilia gene ARL13B lead to the classical form of Jjoubert syndrome. Am J Hum Genet. 83: 170-179. doi:10.1016/j.ajhg.2008.06.023 147: dev190173. doi:10.1242/dev.190173

Caspary, T., M. J. Garcia-Garcia, D. Huangfu, J. T. Eggenschwiler, M. R. Wyler et al., 2002 Mouse Dispatched homolog1 is required for long-range, but not juxtacrine, Hh signaling. Curr Biol. 12: 1628-1632. doi:10.1016/s)960-9822(02)01147-8

Caspary, T., C. E. Larkins, and K. V. Anderson, 2007 The graded response to Sonic Hedgehog depends on cilia architecture. Dev Cell. 12: 767-778.

Charron, F., E. Stein, J. Jeong, A. P. McMahon, and M. Tessier-Lavigne, 2003 The morphogen sonic hedgehog is an axonal chemoattractant that collaborates with

613 Chavez, M., S. Ena, J. Van Sande, A. de Kerchove d'Exaerde, S. Schurmans et al., 2015 Modulation of ciliary phosphoinositide content regulates trafficking and Sonic hedgehog signaling output. Dev Cell. 34: 338-350. 
617 Chiang, C., Y. Litingtung, E. Lee, K. E. Young, J. L. Corden et al., 1996 Cyclopia and defective axial patterning in mice lacking Ssonic hedgehog gene function. Nature. 383: 407-413. Doi:10.1038/383407a0

Chih, B., P. Liu, Y. Chinn, C. Chalouni, L. G. Komuves et al., 2011 A ciliopathy complex at the transition zone protects the cilia as a privileged membrane domain. Nat

Chizhikov, V. V., J. Davenport, Q. Zhang, E. K. Shih, O. A. Cabello et al., 2007 Cilia proteins control cerebellar morphogenesis by promoting expansion of the granule progenitor pool. J Neurosci. 27: 9780-9789. doi:10.1523/JNEUROSCI.558606.2007

Christopher, K. J., B. Wang, Y. Kong, and S. D. Weatherbee, 2012 Forward genetics uncovers Transmembrane protein 107 as a novel factor required for ciliogenesis and Sonic hedgehog signaling. Dev Biol. 368: 382-392. Molecular diagnostics of Meckel-Gruber syndrome highlights phenotypic differences between MKS1 and MKS3. Hum Genet. 121: 591-599. doi:10.1007/s00439-007-0341-3 doi:10.1016/j.ydbio.2012.06.008

Constable, S., A. B. Long, K. A. Floyd, S. Schurmans, and T. Caspary, 2020 The ciliary phosphatidylinositol phosphatase Inpp5e plays positive and negative regulatory roles in Shh signaling. Development. 147: dev183301. doi:10.1242/dev.183301 
640 Davey, M. G., I. R. Paton, Y. Yin, M. Schmidt, F. K. Bangs et al., 2006 The chicken talpid3 gene encodes a novel protein essential for Hedgehog signaling. Genes Dev. 20: 1365-1377. doi:10.1101/gad.369106

643

Delous, M., L. Baala, R. Salomon, C. Laclef, J. Vierkotten et al., 2007 The ciliary gene RPGRIP1L is mutated in cerebello-oculo-renal syndrome (Joubert syndrome type B) and Meckel syndrome. Nat Genet. 39: 875-881. doi:10.1038/ng2039

Deshpande, O., R. Z. Lara, O. R. Zhang, D. Concepcion, and B. A. Hamilton, 2020 ZNF423 patient variants, truncations, and in-frame deletions in mice define an allele-dependent range of midline brain abnormalities. PLoS Genet. 16: e1009017. doi:10.1371/journal.pgen.1009017

Doherty, D., 2009 Joubert syndrome: Insights into brain development, cilium biology, and complex disease. Semin Pediatr Neurol. 16: 143-154. doi:10.1016/j.spen.2009.06.002

Dowdle, W. E., J. F. Robinson, A. Kneist, M. S. Sirerol-Piquer, S. G. M. Frints et al., 2011 Disruption of a ciliary B9 protein complex causes Meckel syndrome. Am J Hum Genet. 89: 94-110. doi:10.1016/j.ajhg.2011.06.003

Ferent, J., S. Constable, E. D. Gigante, P. T. Yam, L. E. Mariani et al., 2019 The ciliary protein Arl13b functions outside of the primary cilium in Shh-mediated axon guidance. Cell Rep. 29: 3356-3366.e3353. doi:10.1016/j.celrep.2019.11.015

Fink, A. J., C. Englund, R. A. M. Daza, D. Pham, C. Lau et al., 2006 Development of the deep cerebellar nuclei: Transcription factors and cell migration from the rhombic lip. J Neurosci. 26: 3066-3076. doi:10.1523/JNEUROSCI.5203-05.2006 
662 Frikstad, K-A. M., E. Molinari, M. Thoresen, S. A. Ramsbottom, F. Hughes et al., 2019 A CEP104-CSPP1 complex is required for formation of primary cilia competent in Hedgehog signaling. Cell Rep. 28: 1907-1922.e6 doi:10.1016/j.celrep.2019.07.025

Garcia-Gonzalo, F. R., K. C. Corbit, M. S. Sirerol-Piquer, G. Ramaswami, E. A. Otto et al., 2011 A transition zone complex regulates mammalian ciliogenesis and ciliary membrane composition. Nat Genet. 43: 776-784. doi:10.1038/ng.891

Garcia-Gonzalo, F. R., S. C. Phua, E. C. Roberson, G. Garcia 3rd, M. Abedin et al., 2015 Phosphoinositides regulate ciliary protein trafficking to modulate Hedgehog signaling. Dev Cell. 34: 400-409. doi:10.1016/j.devcel.2015.08.001

Gaudet, M., A-G. Fara, I. Beritognolo, and M. Sabatti, 2009 Allele-specific PCR in SNP genotyping. Methods Mol Biol. 578: 415-424. doi:10.1007/978-1-60327-411-1_26

Gigante, E. D., M. R. Taylor, A. A. Ivanova, R. A. Kahn, and T. Caspary, 2020. ARL13B regulates Sonic hedgehog signaling from outside primary cilia. eLife. 9: e50434. doi:10.7554/eLife.50434 Genesis. 44: 611-621. doi:10.1002/dvg.20256

680 Gotthardt, K., M. Lokaj, C. Koerner, N. Falk, A. Giessl et al., 2015 A G-protein activation cascade from Arl13b to Arl3 and implications for ciliary targeting of lipidated proteins. eLife. 4: e11859. doi:10.7554/eLife.11859 
683 Guo, J., J. M. Otis, S. K. Suciu, C. Catalano, L. Xing et al., 2019 Primary cilia signaling promotes axonal tract development and is disrupted in Joubert syndrome-related disorders models. Dev Cell. 51: 759-774 e755. doi:10.1016/j.devcel.2019.11.005

Hagemann, A. I. H., and S. Scholpp, 2012 The tale of the three brothers - Shh, Wnt, and Fgf during development of the thalamus. Front Neurosci. 6: 76. doi:10.3389/fnins.2012.00076

Haldipur, P., K. A. Aldinger, S. Bernardo, M. Deng, A. E. Timms et al., 2019 Spatiotemporal expansion of primary progenitor zones in the developing human

Hata, A., J. Seoane, G. Lagna, E. Montalvo, A. Hemmati-Brivanlou et al., 2000 OAZ uses distinct DNA- and protein-binding zinc fingers in separate BMP-Smad and Olf signaling pathways. Cell. 100: 229-240. doi:10.1016/s0092-8674(00)81561-5

Hazen, V. M. , M. G. Andrews, L. Umans, E. B. Crenshaw 3rd, A. Zwijsen et al., 2012 BMP receptor-activated Smads confer diverse functions during the development of the dorsal spinal cord. Dev Biol. 367: 216-227.

Heydemann, A., L. C. Nguyen, and E. B. Crenshaw 3rd, 2001 Regulatory regions from the Brn4 promoter direct LACZ expression to the developing forebrain and neural

702 Hopp, K., C. M. Heyer, C. J. Hommerding, S. A. Henke, J. L. Sundsbak et al., 2011 B9D1 is revealed as a novel Meckel syndrome (MKS) gene by targeted exonenriched next-generation sequencing and deletion analysis. Hum Mol Genet. 20: 2524-2534. doi:10.1093/hmg/ddr151 
706

707

708

709

710

711

712

713

714

715

716

717

718

719

720

721

722

723

724

725

726

727

728

Horner, V. L., and T. Caspary, 2011 Disrupted dorsal neural tube BMP signaling in the cilia mutant Arl13b hnn stems from abnormal Shh signaling. Dev Biol. 355: 4354. doi:10.1016/j.ydbio.2011.04.019

Huang, S., J. Laoukili, M. T. Epping, J. Koster, M. Hölzel et al., 2009 ZNF423 is critically required for retinoic acid-induced differentiation and is a marker of neuroblastoma outcome. Cancer Cell. 15: 328-340. doi:10.1016/j.ccr.2009.02.023

Huangfu, D., A. Liu, A. S. Rakeman, N. S. Murcia, L. Niswander et al., 2003 Hedgehog signalling in the mouse requires intraflagellar transport proteins. Nature. 426: 8387. doi:10.1038/nature02061

Humbert, M. C., K. Weihbrecht, C. C. Searby, Y. Li, R. M. Pope et al., 2012 ARL13B, PDE6D, and CEP164 form a functional network for INPP5E ciliary targeting. Proc Natl Acad Sci U S A. 109: 19691-19696. doi:10.1073/pnas.1210916109

Hynes, A. M., R. H. Giles, S. Srivastava, L. Eley, J. Whitehead et al., 2014 Murine Joubert syndrome reveals Hedgehog signaling defects as a potential therapeutic target for nephronophthisis. Proc Natl Acad Sci U S A. 111: 9893-9898. doi:10.1073/pnas.1322373111

Ivanova, A. A., T. Caspary, N. T. Seyfried, D. M. Duong, A. B. West et al., 2017 Biochemical characterization of purified mammalian ARL13B protein indicates that it is an atypical GTPase and ARL3 guanine nucleotide exchange factor (GEF). J Biol Chem. 292: 11091-11108. doi:10.1074/jbc.M117.784025

Kenney, A. M., and D. H. Rowitch, 2000 Sonic hedgehog promotes G(1) cyclin expression and sustained cell cycle progression in mammalian neuronal 
precursors. Mol Cell Biol. 20: 9055-9067. doi:10.1128/mcb.20.23.90559067.2000

731 Lai, C. K., N. Gupta, X. Wen, L. Rangell, B. Chih et al., 2011 Functional characterization of putative cilia genes by high-content analysis. Mol Biol Cell. 22: 1104-1119. doi:10.1091/mbc.E10-07-0596

Lan, Y., and R. Jiang, 2009 Sonic hedgehog signaling regulates reciprocal epithelialmesenchymal interactions controlling palatal outgrowth. Development. 136: 1387-1396. doi:10.1242/dev.028167 Wnt-dependent cerebellar midline fusion in a mouse model of Joubert syndrome. Nat Med. 17: 726-731. doi:10.1038/nm.2380 factor-like GTPase 13B leads to kidney cysts. J Am Soc Nephrol. 27: 3628-3638. doi:10.1681/ASN.2015091004

746 Lipinski, R. J., C. Song, K. K. Sulik, J. L. Everson, J. J. Gipp et al., 2010 Cleft lip and palate results from Hedgehog signaling antagonism in the mouse: Phenotypic characterization and clinical implications. Birth Defects Res A Clin Mol Teratol. 88: 232-240. doi:10.1002/bdra.20656 
Maria, B. L., K. B. Hoang, R. J. Tusa, A. A. Mancuso, L. M. Hamed et al., 1997 “Joubert syndrome" revisited: key ocular motor signs with magnetic resonance imaging correlation. J Child Neurol. 12: 423-430. doi:10.1177/088307389701200703

\section{3}

754

755

756

Mariani, L. E., M. F. Bijlsma, A. A. Ivanova, S. K. Suciu, R. A. Kahn et al., 2016 Arl13b regulates Shh signaling from both inside and outside the cilium. Mol Biol Cell. 27: 3780-3790. doi:10.1091/mbc.E16-03-0189

Miertzschke, M., C. Koerner, M. Spoerner, and A. Wittinghofer, 2014 Structural insights into the small G-protein Arl13b and implications for Joubert syndrome. Biochem J. 457: 301-311. doi:10.1042/BJ20131097

Munoz-Estrada, J., and R. J. Ferland, 2019 Ahi1 promotes Arl13b ciliary recruitment, regulates Arl13b stability and is required for normal cell migration. $J$ Cell Sci. 132: jcs230680. doi:10.1242/jcs. 230680

Nolan-Stevaux, O., J. Lau, M. L. Truitt, G. C. Chu, M. Hebrok et al., 2009 Gli1 is regulated through Smoothened-independent mechanisms in neoplastic pancreatic ducts and mediates PDAC cell survival and transformation. Genes Dev. 23: 24-36. doi:10.1101/gad.1753809

Nuovo, S., I. Bacigalupo, M. Ginevrino, R. Battini, E. Bertini et al., 2020 Age and sex prevalence estimate of Joubert syndrome in Italy. Neurology. 94: e797-e801. doi:10/1212/WNL.0000000000008996

Onimaru, H., Y. Kumagawa, and I. Homma, 2006 Respiration-related rhythmic activity in the rostral medulla of newborn rats. J Neurophysiol. 96: 55-61. doi:10.1152/jn.01175.2005 
772 Otto, E. A., K. Tory, M. Attanasio, W. Zhou, M. Chaki et al, 2009 Hypomorphic

773

774

775

776

777

778

779

780 mutations in meckelin (MKS3/TMEM67) cause nephronophthisis with liver fibrosis (NPHP11). J Med Genet. 46: 663-670. doi:10.1136/jmg.2009.066613

Parisi, M. A, 2019 The molecular genetics of Joubert syndrome and related ciliopathies: The challenges of genetic and phenotypic heterogeneity. Trans/ Sci Rare Dis. 4: 25-49. doi:10.3233/TRD-190041

Parisi, M. A., D. Doherty, P. F. Chance, and I. A. Glass, 2007 Joubert syndrome (and related disorders) (OMIM 213300). Eur J Hum Genet. 15: 511-521. doi:10.1038/sj.ejhg.5201648

Pasqualato, S., L. Renault, and J. Cherfils, 2002 Arf, Arl, Arp and Sar proteins: A family of GTP-binding proteins with a structural device for 'front-back' communication. EMBO Rep. 3: 1035-1041. doi:10.1093/embo-reports/kvf221

Poretti, A., E. Boltshauser, T. Loenneker, E. M. Valente, F. Brancati et al., 2007 Diffusion tensor imaging in Joubert syndrome. AJNR Am J Neuroradiol. 28: 1929-1933. doi:10.3174/ajnr.A0703

Quisling, R. G., A. J. Barkovich, and B. L. Maria, 1999 Magnetic resonance imaging features and classification of central nervous system malformations in Joubert syndrome. J Child Neurol. 14: 628-635. doi:10.1177/088307389901401002

Rafiullah, R., A. B. Long, A. A. Ivanova, H. Ali, S. Berkel et al., 2017 A novel homozygous ARL13B variant in patients with Joubert syndrome impairs its guanine nucleotide-exchange factor activity. Eur J Hum Genet. 25: 1324-1334. doi:10.1038/s41431-017-0031-0 
794 Ramsbottom, S. A., P. E. Thelwall, K. M. Wood, G. J. Clowry, L. A. Devlin et al., 2020 Mouse genetics reveals Barttin as a genetic modifier of Joubert syndrome. Proc Natl Acad Sci U S A. 117: 1113-1118. doi:10.1073/pnas.1912602117

Reiter, J. F., and W. C. Skarnes, 2006 Tectonic, a novel regulator of the Hedgehog pathway required for both activation and inhibition. Genes Dev. 20: 22-27. doi:10.1101/gad.1363606

Roberson, E. C., W. E. Dowdle, A. Ozanturk, F. R. Garcia-Gonzalo, C. Li et al., 2015 TMEM231, mutated in orofaciodigital and Meckel syndromes, organizes the

Sang, L., J. J. Miller, K. C. Corbit, R. H. Giles, M. J. Brauer et al., 2011 Mapping the NPHP-JBTS-MKS protein network reveals ciliopathy disease genes and pathways. Cell. 145: 513-528. doi:10.1016/j.cell.2011.04.019

Schindelin, J., I. Arganda-Carreras, E. Frise, V. Kaynig, M. Longair et al., 2012 Fiji: an open-source platform for biological-image analysis. Nat Methods. 9: 676-682.

Schrick, J. J., P. Vogel, A. Abuin, B. Hampton, and D. S. Rice, 2006 ADP-ribosylation factor-like 3 is involved in kidney and photoreceptor development. Am J Pathol.

812 Schwarz, N., A. Lane, K. Jovanovic, D. A. Parfitt, M. Aguila et al., 2017 Arl3 and RP2 regulate the trafficking of ciliary tip kinesins. Hum Mol Genet. 26: 2480-2492. doi:10.1093/hmg/ddx143 
815 Shaheen, R., K. Szymanska, B. Basu, N. Patel, N. Ewida et al., 2016 Characterizing the morbid genome of ciliopathies. Genome Biol. 17: 242. doi:10.1186/s13059016-1099-5

818 Srour, M., F. F. Hamdan, J. A. Schwartzentruber, L. Patry, L. H. Ospina et al., 2012 Mutations in TMEM231 cause Joubert syndrome in French Canadians. $J$ Med Genet. 49: 636-641. doi:10.1136/jmedgenet-2012-101132

821 Su, C-Y., S. N. Bay, L. E. Mariani, M. J. Hillman, and T. Caspary, 2012 Temporal deletion of Arl13b reveals that a mispatterned neural tube corrects cell fate over time. Development. 139: 4062-4071. doi:10.1242/dev.082321

Thomas, S., M. Legendre, S. Saunier, B. Bessières, C. Alby et al., 2012 TCTN3 mutations cause Mohr-Majewski syndrome. Am J Hum Genet. 91: 372-378.

831 Valente, E. M., F. Brancati, and B. Dallapiccola, 2008 Genotypes and phenotypes of Joubert syndrome and related disorders. Eur J Med Genet. 51: 1-23.

834 Valente, E. M., C. V. Logan, S. Mougou-Zerelli, J. H. Lee, J. L. Silhavy et al., 2010 Mutations in TMEM216 perturb ciliogenesis and cause Joubert, Meckel and related syndromes. Nat Genet. 42: 619-625. doi:10.1038/ng.594 
837 Vierkotten, J., R. Dildrop, T. Peters, B. Wang, and U. Rüther, 2007 Ftm is a novel basal body protein of cilia involved in Shh signaling. Development. 134: 2569-2577.

Weatherbee, S. D., L. A. Niswander, and K. V. Anderson, 2009 A mouse model for Meckel syndrome reveals Mks1 is required for ciliogenesis and Hedgehog signaling. Hum Mol Genet. 18: 4565-4575. doi:10.1093/hmg/ddp422

Wechsler-Reya, R. J., and M. P. Scott, 1999 Control of neuronal precursor proliferation in the cerebellum by Sonic Hedgehog. Neuron. 22: 103-114. doi:10.1016/s0896-

Wu, C., M. Yang, J. Li, C. Wang, T. Cao et al., 2014 Talpid3-binding centrosomal protein Cep120 is required for centriole duplication and proliferation of cerebellar

Yachnis, A. T., and L. B. Rorke, 1999 Neuropathology of Joubert syndrome. J Child Neurol. 14: 655-659. doi:10.1177/088307389901401006

Zhang, X. M., M. Ramalho-Santos, and A. P. McMahon, 2001 Smoothened mutants reveal redundant roles for Shh and Ihh signaling including regulation of L/R symmetry by the mouse node. Cell. 106: 781-792.

855 Zhu, J., H.-T. Wang, Y.-R. Chen, L.-Y. Yan, Y.-Y. Han et al., 2020 The Joubert syndrome gene arl13b is critical for early cerebellar development in zebrafish. 
860 Figure 1: SCPs lacking Arl13b or Smo fail to project to the dorsal thalamus. (A-C)

861 Schematics of injections and fluorescent tracer diffusion shown horizontally (A) or

862 sagittally (B-C). (A) Red dashed arrow depicts dye path in a successful injection from

863 injection site (red X) caudal through the brain and across the midline and into the

864 contralateral cerebellar DCN (red arrowhead). Grey background boxes indicate area of

865 subsequent images: the injection site (INJ) and cerebellum (DCN). (D-I) Representative

866 images of dorsal $(D, F, H)$ or ventral $(E, G, I)$ thalamus injection site (top panel) and

867 cerebellum (middle panel) with the DCN in hatched white circle and magnified (bottom

868 panel) with recoloring to black and white to aid visualization. The retrograde fluorescent

869 tracer is pink-red and sections are stained with DAPI (blue). Numbers indicate the

870 number of positively stained DCN clusters (DCN traced) out of the total number of

871 injected animals. Note that no tracing was observed on ipsilateral side to injection. (D,

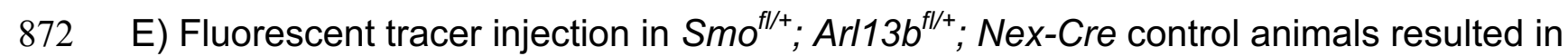

873 contralateral DCN staining in (D) 6/8 dorsal thalamus injections and (E) 8/11 ventral

874 thalamus injections. $(F, G)$ Fluorescent tracer injection in Smo ${ }^{\text {Nex-Cre }}$ animals resulted in

875 contralateral DCN staining in (F) 0/6 dorsal thalamus injections and (G) 4/4 ventral

876 thalamus injections. $(\mathrm{H}, \mathrm{I})$ Fluorescent tracer injection in $\mathrm{Arl13} \mathrm{b}^{\text {Nex-Cre }}$ animals resulted in

877 contralateral DCN staining in $(\mathrm{H}) 1 / 7$ dorsal thalamus injections and (I) 4/4 ventral

878 thalamus injections. Two-tailed Fisher's exact test was performed; only the dorsal

879 injection results were significantly different from the controls $(F: p<0.01 ; H: p<0.05)$

881 Figure 2: SCPs expressing cilia-excluded ARL13B ${ }^{\mathrm{V} 358 \mathrm{~A}}$ project normally to both

882 the dorsal and ventral thalamus. (A-D) Representative images of dorsal (A, C) or 
883 ventral $(B, D)$ thalamus injection site (top panel) and cerebellum (middle panel) with the

884 DCN in hatched white circle and magnified (bottom panel) with recoloring to black and

885 white to aid visualization. Numbers indicate the number of positively stained DCN

886 clusters out of the total number of injected animals. Note that no tracing was observed

887 on the injection's ipsilateral side. $(\mathrm{A}, \mathrm{B})$ Fluorescent tracer injection in $\mathrm{Arl13} b^{\mathrm{V} 358 \mathrm{~A} /+}$

888 control animals resulted in contralateral DCN staining in $(A) 3 / 3$ dorsal thalamus

889 injections and (B) 4/4 ventral thalamus injections. (C-D) Fluorescent tracer injection in

$890 A r 113 b^{V 358 A / V 358 A}$ animals resulted in contralateral DCN staining in (C) 4/4 dorsal

891 thalamus injections (Fisher's exact test, two-tailed, ns, p>0.9) and (D) $3 / 3$ ventral

892 thalamus injections ( $n s, p>0.9)$.

Figure 3: SCPs expressing JS allele $A r l 13 b^{R 79 Q}$ project normally to both the dorsal

895 and ventral thalamus. (A) Schematic showing the protein domain structure of Arl13b.

896 The R79Q mutation occurs in a highly conserved subregion of the GTPase domain,

897 Switch 2 (red). (B) Alignment of protein sequence surrounding amino acid 79 of mouse

898 Arl13b (red highlight) showing that arginine is conserved across multiple species.

899 Sequences used in protein alignment: Homo sapiens NP_878899.1, Mus musculus

900 NP_080853.3, Danio rerio NP_775379.1, Chlamydomonas reinhardtii XP_001691430.1.

901 (C-F) Representative images of dorsal (C, E) or ventral (D, F) thalamus injection site

902 (top panel) and cerebellum (middle panel) with the DCN in hatched white circle and

903 magnified (bottom panel) with recoloring to black and white to aid visualization.

904 Numbers indicate the number of positively stained DCN clusters out of the total number

905 of injected animals. Note that no tracing was observed on the injection's ipsilateral side. 
906 (C, D) Fluorescent tracer injection in $A r l 13 b^{R 79 Q /+}$ control animals resulted in

907 contralateral DCN staining in (C) 4/4 dorsal thalamus injections and (D) $3 / 3$ ventral

908 thalamus injections. (E-F) Fluorescent tracer injection in Arl13b $b^{R 79 Q / R 79 Q}$ animals

909 resulted in contralateral DCN staining in (E) 3/3 dorsal thalamus injections (Fisher's

910 exact test, two-tailed, $n s, p>0.9$ ) and $(F) 3 / 4$ ventral thalamus injections ( $n s, p>0.9$ ).

911

912 Figure 4: Mouse embryos expressing JS allele Arl13 $b^{R 79 Q}$ display normal cell

913 patterning in the neural tube. Shh, Olig2, Pax6 and Arl13b staining of E10.5 Arl13b

$914(\mathrm{n}=3), \operatorname{Arl13} b^{R 79 Q / R 79 Q}(\mathrm{n}=3), \operatorname{Arl13}^{R 79 Q / \Delta}(\mathrm{n}=3)$, and $\operatorname{Arl13b^{\Delta /\Delta }}(\mathrm{n}=3)$ mouse neural tubes.

915 Scale bar $=100$ micrometers in A-L or 10 micrometers in M-P. (A-D) Shh is visible in the 916 notochord and floorplate of (A) $A r l 13 b^{+/+}$, (B) $A r l 13 b^{R 79 Q / R 79 Q}$ and (C) $A r l 13 b^{R 79 Q / \Delta}$ neural

917 tubes but absent from the floorplate of (D) Arl13b $b^{\Delta / \Delta}$ embryos. (E-H) Olig2 stains the

918 motor neuron precursor domain in (E) $A r l 13 b^{+/+},(\mathrm{F}) A r l 13 b^{R 79 Q / R 79 Q}$ and (G) $A r l 13 b^{R 79 Q / \Delta}$

919 embryos and stains an expanded domain in (H) Arl13b $b^{N / \Delta}$ embryos. (I-L) Pax6

920 expression is visible in the dorsal neural tube in (I) $A r l 13 b^{+/+},(\mathrm{J}) A r l 13 b^{R 79 Q / R 79 Q}$ and (K)

$921 A r l 13 b^{R 79 Q / \Delta}$ neural tubes but shifted dorsally in (L) Arl13 $b^{\Delta / \Delta}$ neural tubes. (M-P) Arl13b

922 is localized to cilia visible in the ventral lumen of $(\mathrm{M}) A r l 13 b^{+/+},(\mathrm{N}) A r l 13 b^{R 79 Q / R 79 Q}$ and

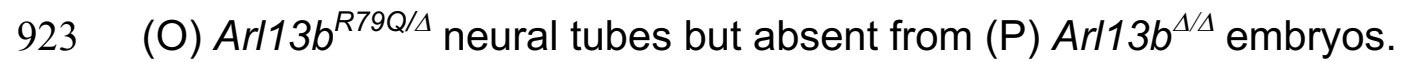

925 Figure 5: $\boldsymbol{A} \mathbf{A} \mathbf{1 3} \boldsymbol{b}^{R 79 Q}$ mutation does not affect cerebellar width. (A) Representative

926 surface-facing images of cerebella from control and $A r l 13 b^{R 79 Q / R 79 Q}$ mutant mice.

927 Scalebar $=1 \mathrm{~mm}$, black line indicates where cerebellar width was measured, red line

928 indicates where vermis width was measured, gray line indicates where cerebellar 
929 hemisphere height was measured, blue line indicates where vermis height was

930 measured. (B) Ratios of $A r l 13 b^{R 79 Q / R 79 Q}$ mutant to control measurements of sex- and

931 age-matched pairs of mice showed no significant difference. Cerebellar and vermis

932 measurements were determined from surface views (symbol colors match the lines in

933 A), body and dissected brain weights were determined using a standard lab scale. Each

934 symbol represents a pair of sex- and age-matched animals: females are represented as

935 circles and males are represented as triangles.

937 Figure 6: Pan-neuronal deletion of $A r l 13 b$ results in a small cerebellum. (A)

938 Representative images of cerebella from control and Arl13b $b^{\text {Brn4-Cre }}$ mutant mice.

939 Scalebar $=1 \mathrm{~mm}$. (B) The ratio of $A r l 13 b^{\text {Brn4-Cre }}$ mutant to control cerebellar width was

940 reduced in both females and males (one-sample t-test: $p<0.1$, single asterisk). The ratio

941 of $A r l 13 b^{\text {Brn4-Cre }}$ mutant to control vermis width was reduced in female and male age

942 matched pairs (one-sample t-test: $\mathrm{p}<0.0001$, four asterisks). While Arl13b ${ }^{\text {Brn4-Cre }}$ mutants

943 had moderately lower body weights than controls (one-sample t-test: $p<0.1$, single

944 asterisk), their brains were slightly heavier, likely due to hydrocephaly. Each symbol

945 represents a pair of sex- and age-matched animals: females are represented as circles

946 and males are represented as triangles.

948 Figure 7: Mice expressing cilia-excluded $A r l 13 b^{V 358 A}$ have cerebella of normal

949 width. (A) Representative images of cerebella from control and Arl13b ${ }^{\text {V358A/V358A }}$ mutant

950 mice. Scalebar $=1 \mathrm{~mm}$. (B) Ratios of $A r 113 b^{V 358 A / V 358 A}$ mutant to control measurements

951 of sex- and age-matched pairs of mice showed no significant differences (one-sample t- 
bioRxiv preprint doi: https://doi.org/10.1101/2021.01.29.428892; this version posted April 28, 2021. The copyright holder for this preprint (which

was not certified by peer review) is the author/funder, who has granted bioRxiv a license to display the preprint in perpetuity. It is made available under aCC-BY-NC 4.0 International license.

952 test). Each dot represents a pair of sex- and age-matched animals: females are

953 represented as circles and males are represented as triangles.

954 
bioRxiv preprint doi: https://doi.org/10.1101/2021.01.29.428892; this version posted April 28, 2021. The copyright holder for this preprint (which was not certified by peer review) is the author/funder, who has granted bioRxiv a license to display the preprint in perpetuity. It is made

A
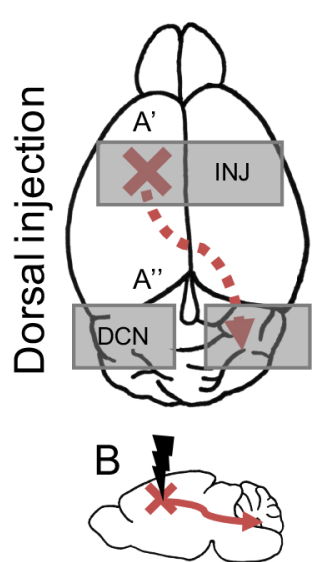

D
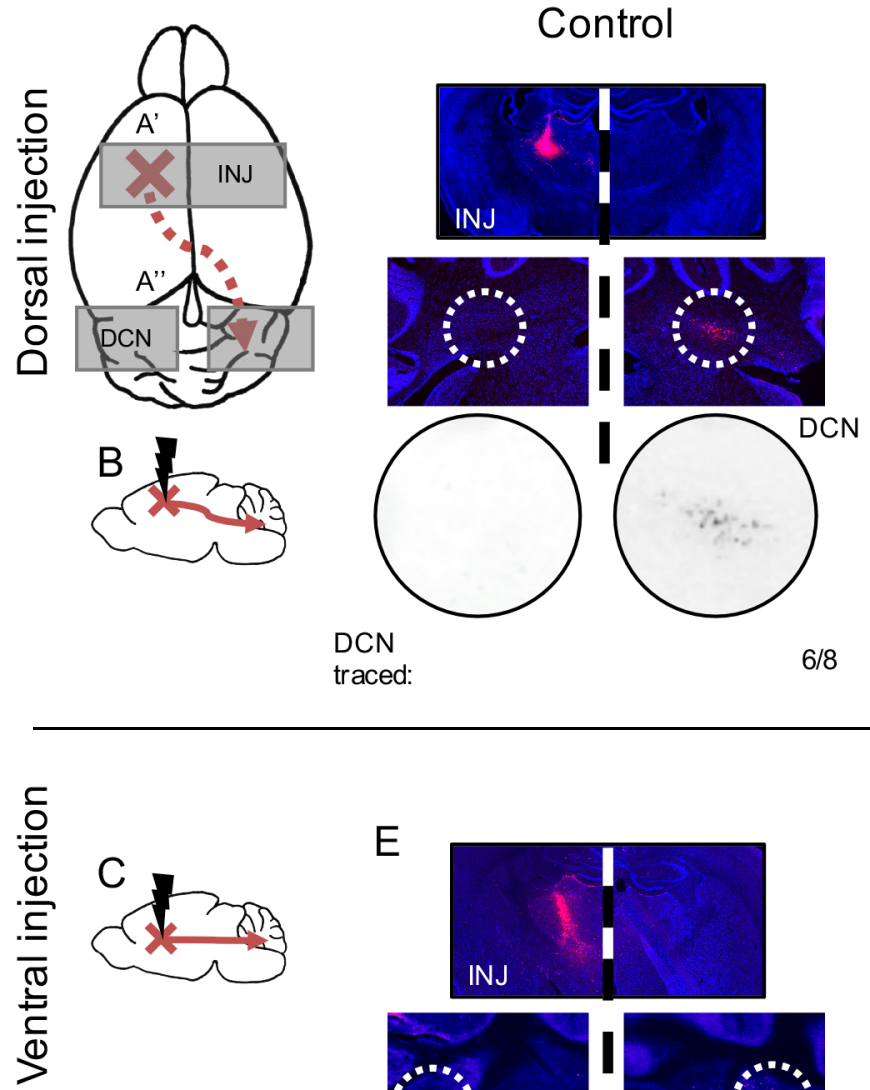
available under aCC-BY-NC 4.0 International license.

$\mathrm{H}$
$F$
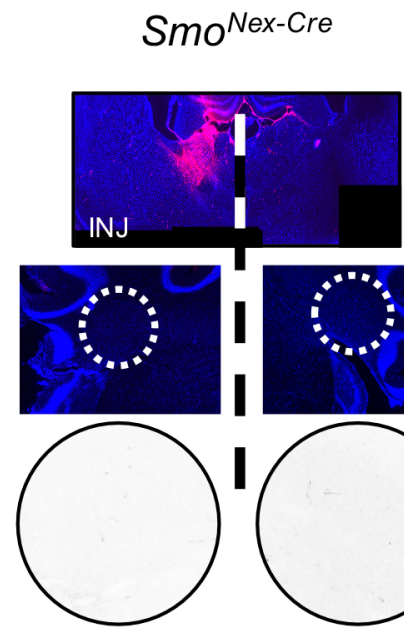
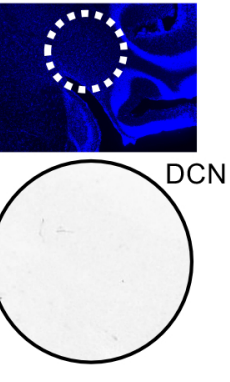

$0 / 6$
Arl13b $b^{\text {Nex-Cre }}$
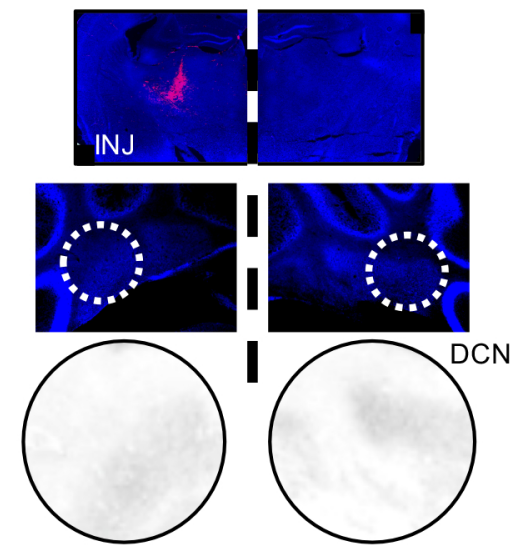

$1 / 7$
E
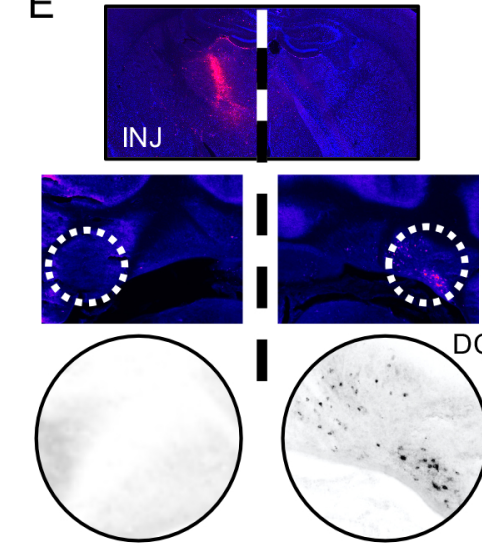

DCN

traced:

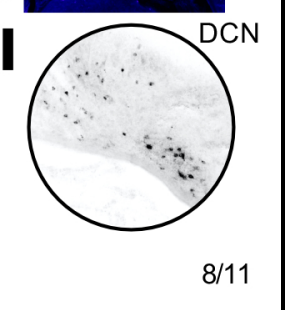

G

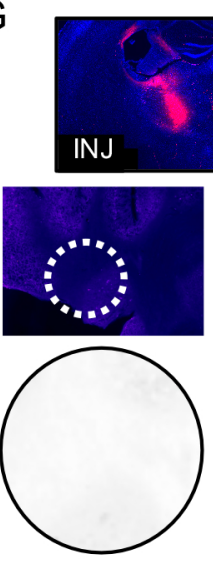

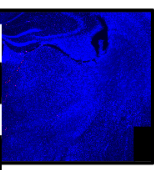

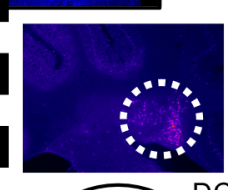

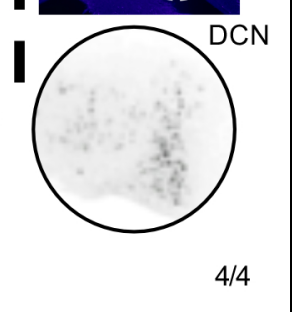
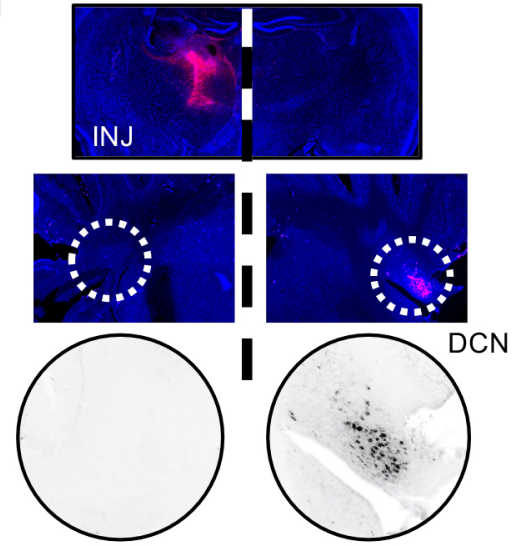
bioRxiv preprint doi: https://doi.org/10.1101/2021.01.29.428892; this version posted April 28, 2021. The copyright holder for this preprint (which was not certified by peer review) is the author/funder, who has granted bioRxiv a license to display the preprint in perpetuity. It is made A

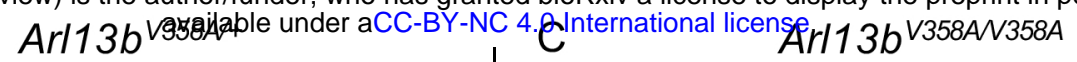

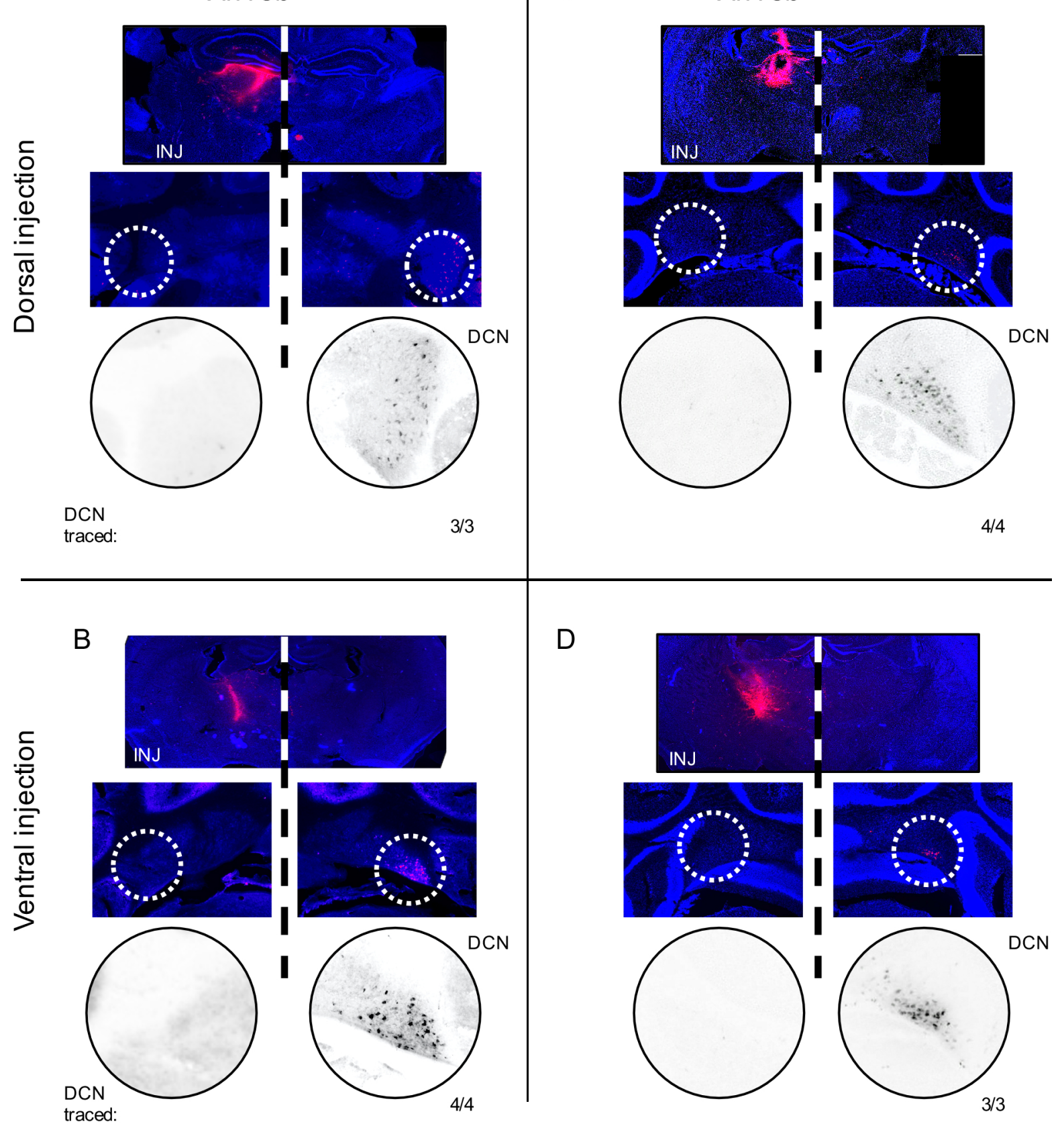


bioRxiv preprint doi: https://doi.org/10.1101/2021.01.29.428892; this version posted April 28, 2021. The copyright holder for this preprint (which was not certified by peer review) is the author/funder, who has granted bioRxiv a license to display the preprint in perpetuity. It is made available under aCC-BY-NC 4.0 International license.

A

$\mathrm{N}$

\begin{tabular}{|c|c|c|c|}
\hline Switch 1 Switch 2 & Poiled-coil & Pro-rich \\
\hline R79Q & GTPase & & V358A \\
\hline
\end{tabular}

B

Switch 1

Switch 2

Human PTVGFSKINLROGKFEVTIEDLGGGIRIRGIWKNYYAESYGVIFVVDSSD 100

Mouse PTVGFSKIDLROGKFOVTIFDLGGGKRIRGIWKNYYAESYGVIFVVDSSD 100

Zebrafish PTVGFS KVDLKOGKFEVTIFDLGGGKRIRGIWKNYYSESYGVVFVVDSSD 100

Chlamy PTFGFN STTLNEGKYKIEV FDLGGKNIRGVWK KYLAEVHA IVYVVDAAD 98

R79Q

C

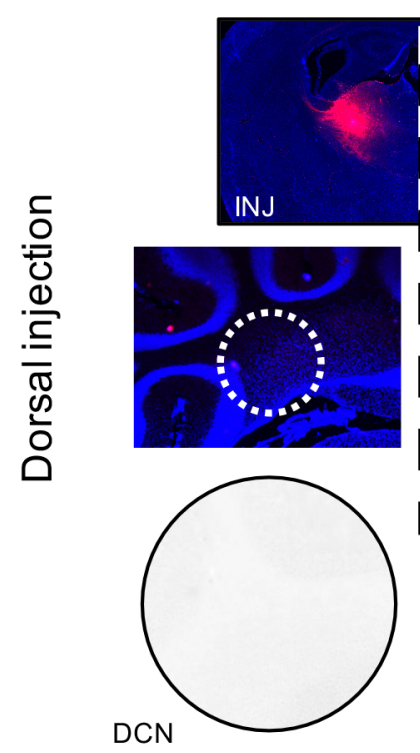

traced:
$\operatorname{Arl13} b^{R 79 Q /+}$
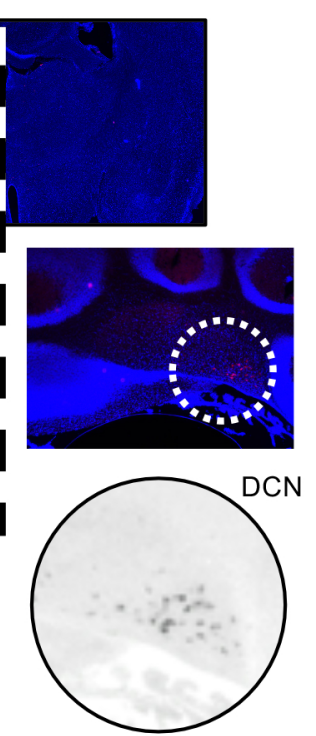

$4 / 4$
$E$

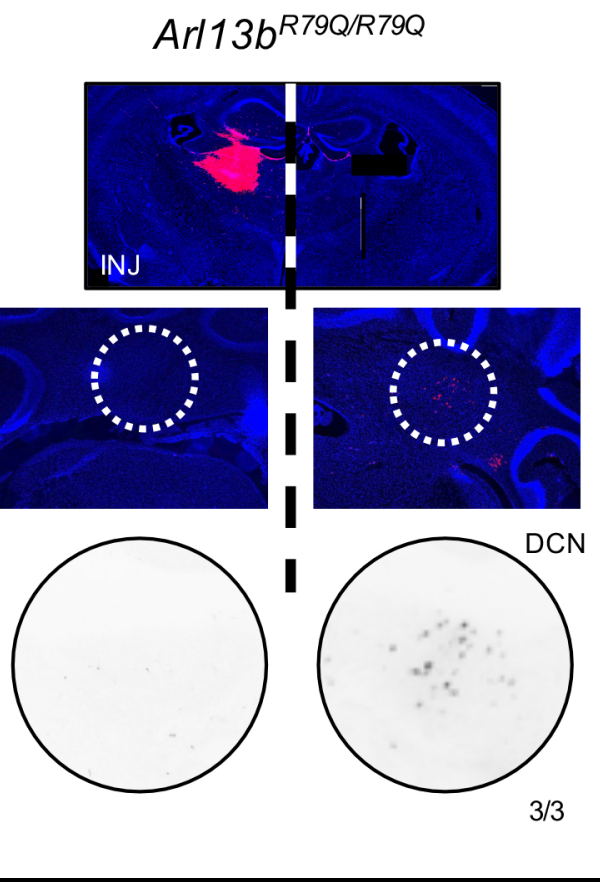

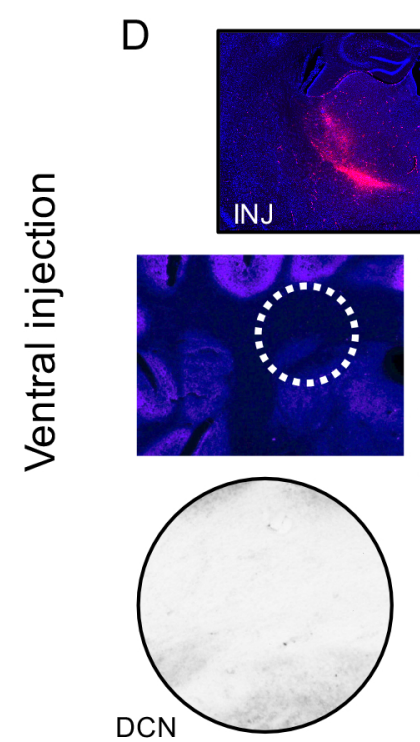

traced:
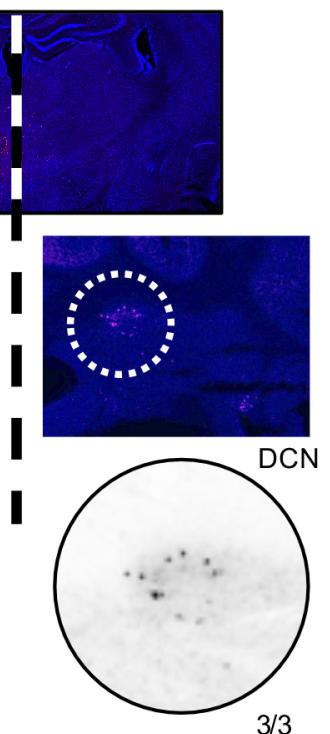

$\mathrm{F}$

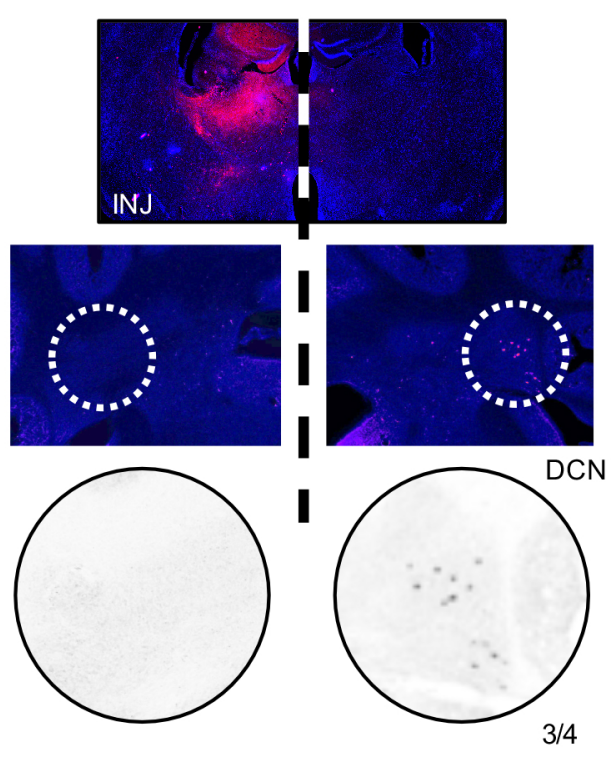


bioRxiv preprint doi: https://doi.org/10.1101/2021.01.29.428892; this version posted April 28, 2021. The copyright holder for this preprint (which was not certified by peer review) is the author/funder, who has granted bioRxiv a license to display the preprint in perpetuity. It is made available under aCC-BY-NC 4.0 International license.
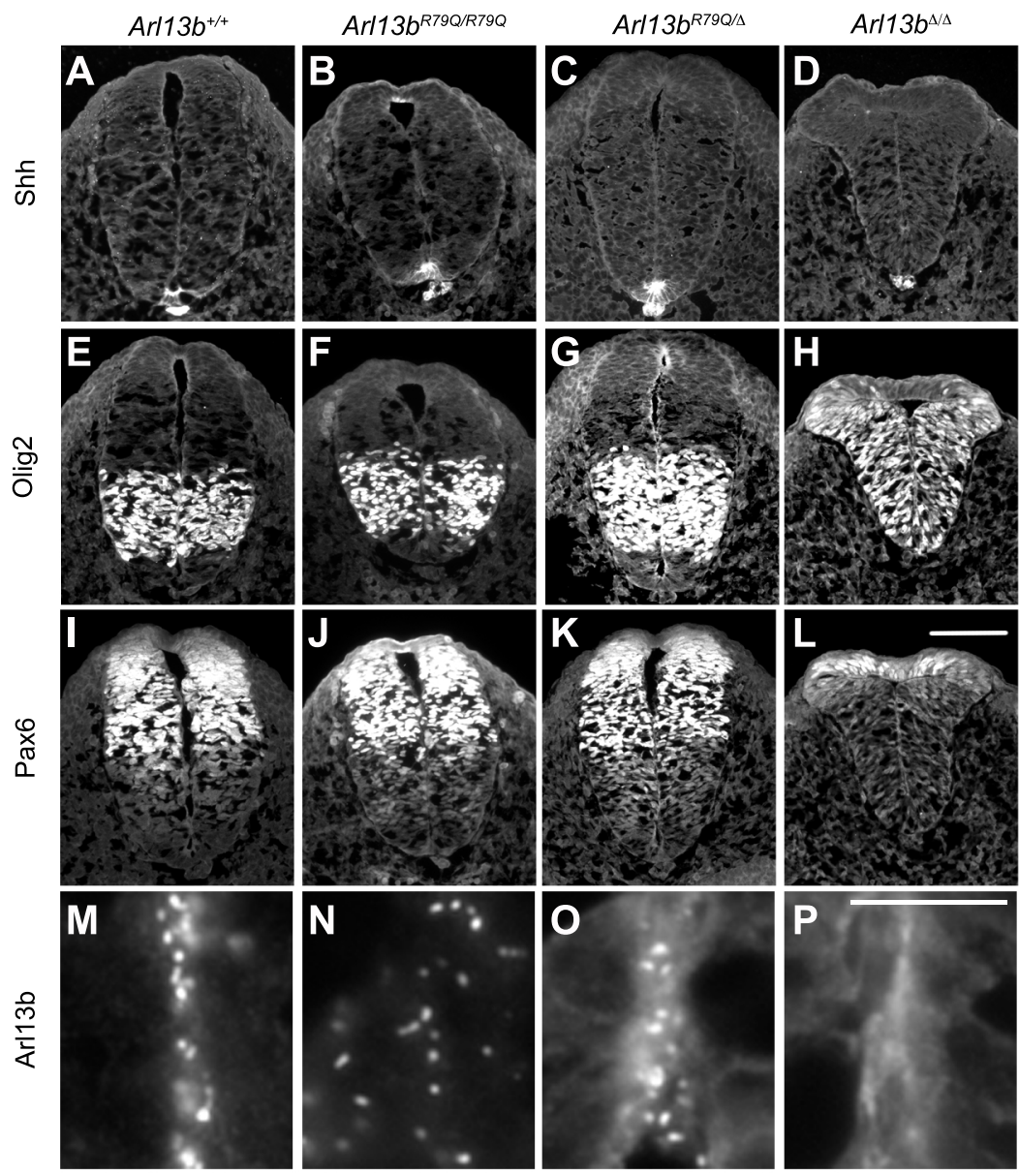
bioRxiv preprint doi: https://doi.org/10.1101/2021.01.29.428892; this version posted April 28, 2021. The copyright holder for this preprint (which was not certified by peer review) is the author/funder, who has granted bioRxiv a license to display the preprint in perpetuity. It is made available under aCC-BY-NC 4.0 International license.
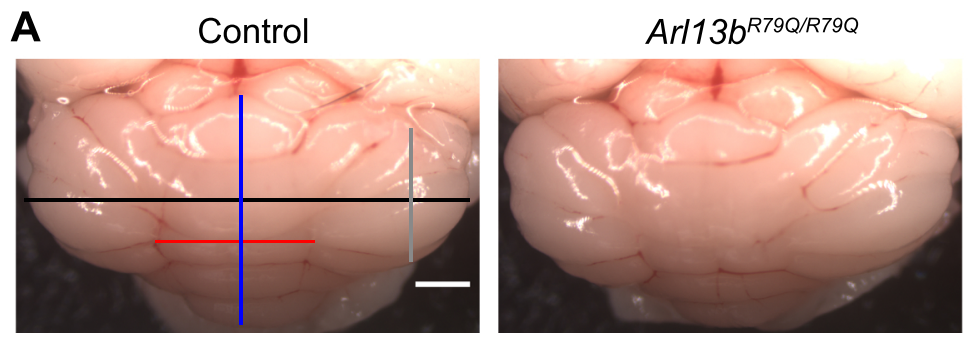

B

Ar/136 $b^{R 79 Q}$

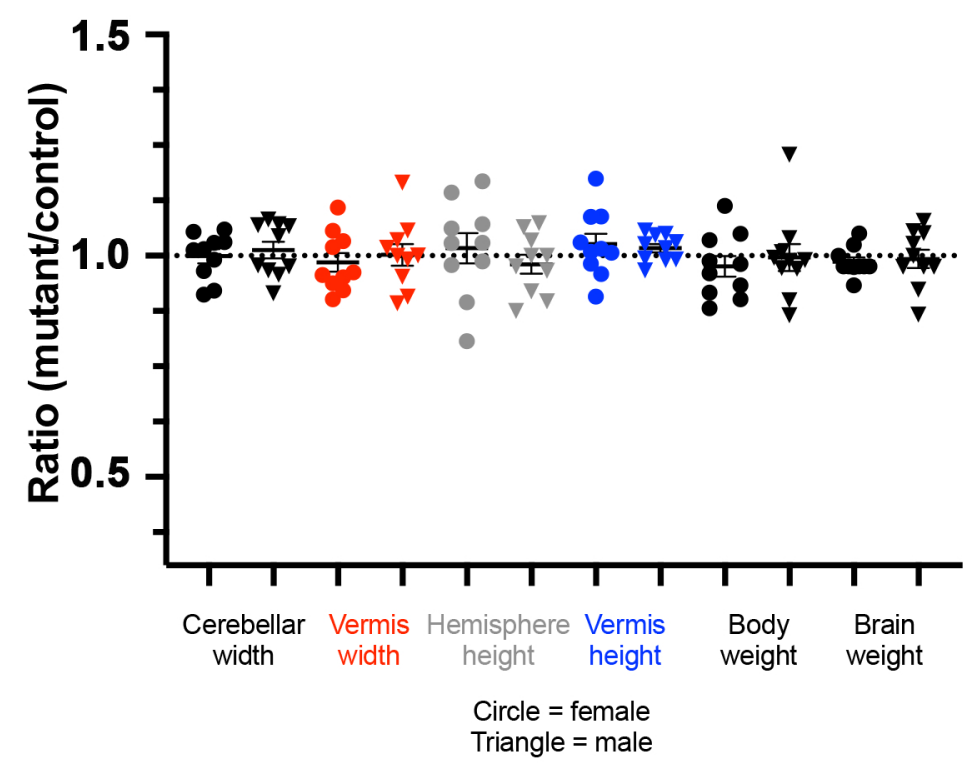



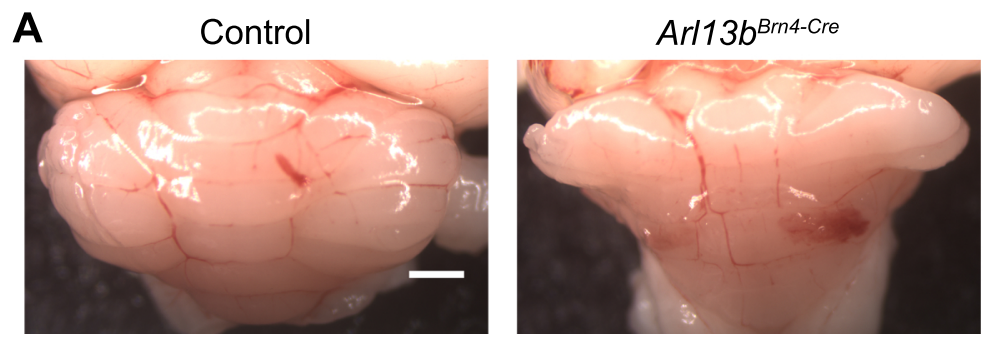

B

Arl13b $b^{\text {Brn4-Cre }}$

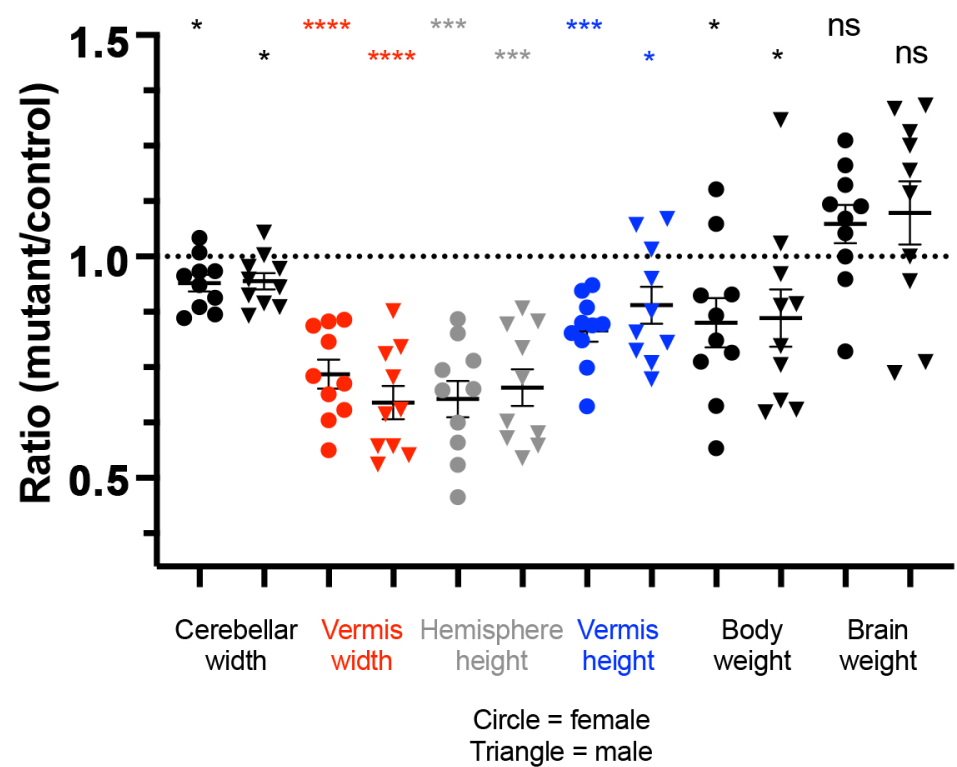


bioRxiv preprint doi: https://doi.org/10.1101/2021.01.29.428892; this version posted April 28, 2021. The copyright holder for this preprint (which was not certified by peer review) is the author/funder, who has granted bioRxiv a license to display the preprint in perpetuity. It is made available under aCC-BY-NC 4.0 International license.

A

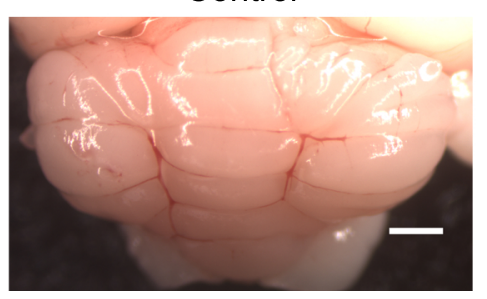

B

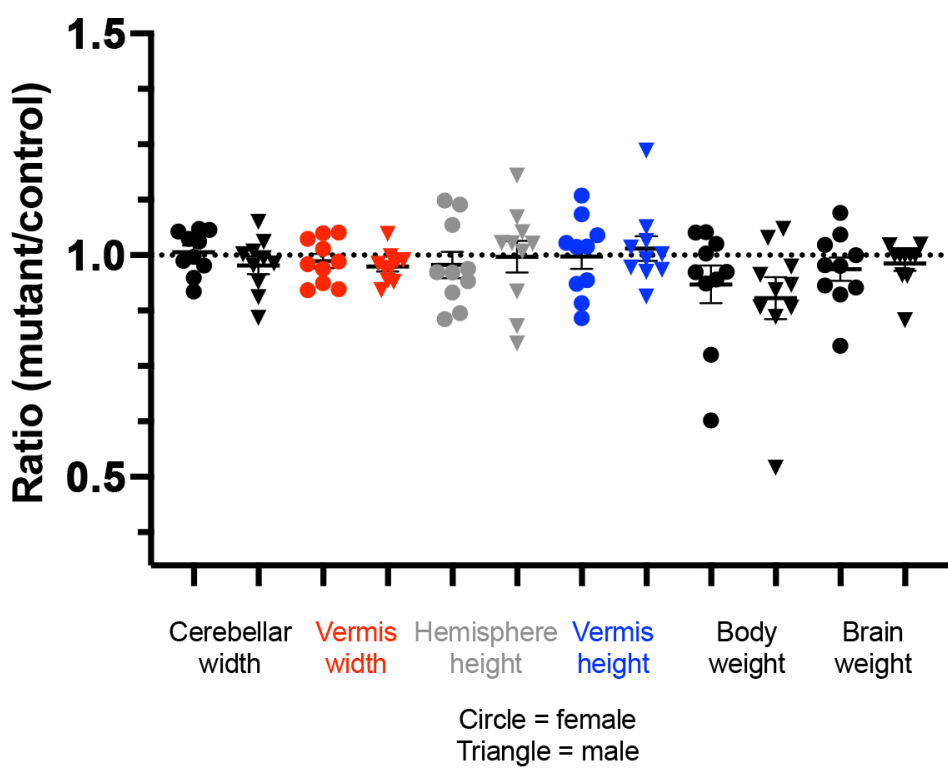

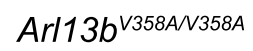

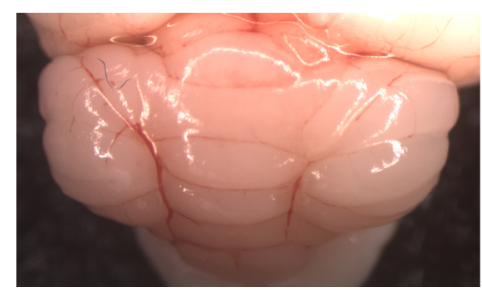

$A r l 13 b^{V 358 A}$

Triangle 